\title{
Three essays in empirical financial economics
}

\author{
by
}

\author{
Timothy Grieder
}

A thesis submitted to the Faculty of Graduate and Postdoctoral Affairs in partial fulfillment of the requirements for the degree of

\section{Doctor of Philosophy \\ in}

\section{Economics}

\author{
Department of Economics \\ Carleton University \\ Ottawa, Ontario, Canada
}

(c) 2018

Timothy Grieder 


\section{Abstract}

In this thesis, I add to the literature which uses microdata to assess how economic outcomes are influenced by the financial condition of firms and households.

In my first chapter, I analyze whether leverage impacts the growth rates of capital expenditures and employment for US and Canadian publicly traded firms in a nonlinear manner. I find that the negative marginal impact of leverage on future growth tends to be higher for firms in higher leverage quartiles for firms with similar growth prospects. I also show that for firms with similar leverage, the impact of leverage on future growth is larger for firms with low growth opportunities compared to those with better growth opportunities. These findings provide new evidence supporting the use of debt to reduce the agency conflicts between shareholders and managers for firms with low growth opportunities.

The second chapter of my thesis challenges the findings of a lead AER article which had analyzed how a firm's investment responds to changes in its collateral values. I demonstrate that their results are highly sensitive to arbitrary Winsorization thresholds. I also show that a firm's investment responds to shocks to national real estate prices rather than shocks to the value of collateral it actually owns. The extent to which real estate shocks affect corporate investment - the collateral channeltherefore, remains an open question.

The final chapter of my thesis analyzes the impact of macroprudential housing finance rules changes in Canada between 2005 and 2010. I start by combining loan- 
level administrative data with household-level survey data to determine the financial condition of potential first time homebuyers in Canada. I then use a microsimulation model of mortgage demand to determine the impact of rule changes on potential first time homebuyers. Policies targeting the loan-to-value ratio are found to have a larger impact than policies targeting the debt-service ratio, such as amortization. In addition, I show that loan-to-value policies have a larger role to play in reducing default than income-based policies.

Disclaimer, the views in this thesis are mine and do not necessarily reflect those of the Bank of Canada. 
To Katherine and Emma Grieder,

Your endless patience and encouragement were invaluable to me during my studies. I am forever grateful to you both. 


\section{Acknowledgements}

I thank my supervisor, Hashmat Khan, for the endless encouragement and support he provided to me while I was completing my thesis. I learned an incredible amount from him over this time period, especially during our joint work which resulted in the second chapter of my thesis. I also thank my other committee members: Nilanjan Basu, Michael McIntyre, Francesca Rondina, Eric Stephens, and Marcel Voia. Their feedback and suggestions greatly improved the quality of my thesis.

I also thank the economic faculties at Carleton University and the University of Ottawa for the wonderful instruction I received during the first two years of the program as well as Marge Brooks for all the help she provided along the way.

I also extend thanks to my co-authors of the third chapter of my thesis: Jason Allen, Brian Petersen and Tom Roberts. I thoroughly enjoyed our collaboration while writing this paper.

Lastly, I extend thanks to my fellow graduate student and friend Anderson Nzanbandora. The study sessions in the Tim Noël room were immensely helpful in preparing for the comprehensive exams. 


\section{Contents}

$\begin{array}{ll}\text { Abstract } & \text { ii }\end{array}$

Acknowledgements $\quad$ v

List of Tables $\quad$ ix

List of Figures $\quad x$

1 Non-linear impacts of leverage on firm growth 1

1.1 Introduction . . . . . . . . . . . . . . . . 1

1.2 Data . . . . . . . . . . . . . . . . . . . . . 4

1.3 Empirical Results . . . . . . . . . . . . . . . . . . . . . . . . 10

1.3.1 First Stage Capital Structure Regressions . . . . . . . . . . . 10

1.3.2 Firm-level Growth Regressions . . . . . . . . . . . . . . . 11

1.3.3 Robustness Check . . . . . . . . . . . . . . . . . . . . 18

1.4 Conclusion . . . . . . . . . . . . . . . . . . . . . . . . 21

1.5 Data Appendix . . . . . . . . . . . . . . . . . . . . 22

2 Do real estate shocks affect corporate investment? 23

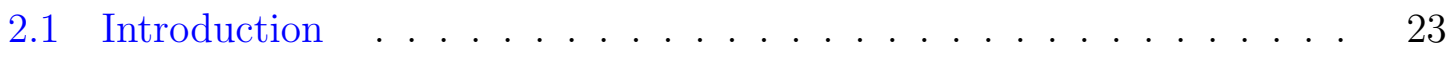

2.2 Winsorization . . . . . . . . . . . . . . . . . . 24

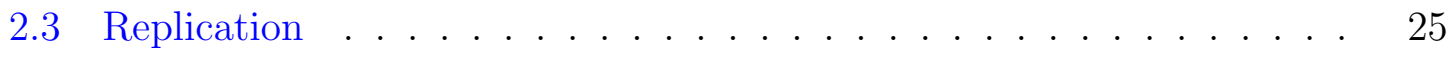


2.4 The Effect of Winsorization . . . . . . . . . . . . .

2.4.1 Do Extreme Values Represent Firms Without Collateral Constraints? . . . . . . . . . . . . . . . . . 31

2.4.2 Are Extreme Values Data Errors? . . . . . . . . . . . . . . . 32

2.5 National, Rather Than Local, Shocks to Real Estate Prices Matter for Investment . . . . . . . . . . . . . . . . . . . . . . 32

2.6 Conclusion . . . . . . . . . . . . . . . . . . . . . . . . 35

3 The Impact of Macroprudential Housing Finance Tools in Canada 36

3.1 Introduction . . . . . . . . . . . . . . . . 36

3.2 Institutional Background . . . . . . . . . . . . . . . . . . . 42

3.3 Mortgage Access Constraints and Rule Changes . . . . . . . . . . 43

3.3.1 Mortgage insurance constraints . . . . . . . . . . . . . . 43

3.3 .2 Rule changes . . . . . . . . . . . . . . . . . . . 44

3.4 Data . . . . . . . . . . . . . . . . . 45

3.4 .1 Mortgage insurance data . . . . . . . . . . . . 45

3.4 .2 Data-driven analysis . . . . . . . . . . . . . . . . . . 49

3.5 Microsimulation Model . . . . . . . . . . . . . . . . . . . . . . . . 54

3.5.1 First-Time Homebuyers _. . . . . . . . . . . . 55

3.5 .2 Calibration . . . . . . . . . . . . . . . . . . 59

3.5.3 Housing Market . . . . . . . . . . . . . . . . . . . . . 64

3.5 .4 Results . . . . . . . . . . . . . . . . . . . 65

3.5.5 Discussion . . . . . . . . . . . . . . . . . . 73

3.6 Conclusion . . . . . . . . . . . . . . . . . . . . . . . . . . 75

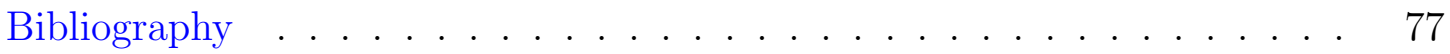




\section{List of Tables}

1.1 List of first stage regression variables $\ldots \ldots \ldots \ldots \ldots$

1.2 List of second stage regression variables . . . . . . . . . 7

1.3 Summary Statistics of US data used in the first stage regression . . . 9

1.4 Summary Statistics of US data used in the second stage regression . . 9

1.5 Summary Statistics of Canadian data used in the first stage regressions 9

1.6 Summary Statistics of Canadian data used in the second stage regressions 9

1.7 First Stage Capital Structure Regressions . . . . . . . . . . . . . 11

1.8 The impact of leverage on US firm growth $\ldots \ldots \ldots \ldots \ldots$

1.9 The impact of leverage on Canadian firm growth . . . . . . . . . . 12

1.10 The impact of leverage on US firm growth for high and low growth firms 14

1.11 The impact of leverage on Canadian firm growth for high and low growth firms . . . . . . . . . . . . . . . . 14

1.12 The non-linear impact of leverage on US firm growth for high and low growth firms . . . . . . . . . . . . . . 16

1.13 The non-linear impact of leverage on Canadian firm growth for high

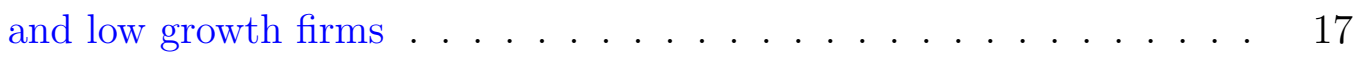

1.14 Non-linear impacts of leverage on future growth US Firms by leverage

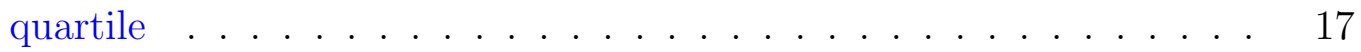

1.15 Non-linear impacts of leverage on future growth Canadian Firms by leverage quartiles $\ldots \ldots \ldots \ldots \ldots \ldots \ldots$ 
1.16 The non-linear impact of leverage on US firm growth for high and low growth firms controlling for industry effects . . . . . . . . . . . . . . 19

1.17 The non-linear impact of leverage on Canadian firm growth for high and low growth firms controlling for industry effects . . . . . . . . . 20

1.18 Non-linear impacts of leverage on future growth of US firms by leverage quartile industry adjusted . . . . . . . . . . . . . . . . 20

1.19 Non-linear impacts of leverage on future growth of Canadian firms by leverage quartiles ...................... . . . . 20

2.1 Replication of CST . . . . . . . . . . . . . . . 28

2.2 Summary Statistics for $I N V_{i t}$ and $R E V_{\text {Value }}$ it . . . . . . . . . . 30

2.3 Real Estate holdings of high investing firms . . . . . . . . . . . 31

2.4 Real Estate Prices and Investment Behaviour: Local versus Aggregate Real Estate Shocks . . . . . . . . . . . . . . . . . . 34

3.1 Summary statistics of transaction-level data for new purchases . . . . 47

3.2 Impact of loosening macroprudential policy changes . . . . . . . . . 52

3.3 Impact of tightening macroprudential policy changes . . . . . . . . 53

3.4 Use of microdata in the calibration strategy . . . . . . . . . . . 60

3.5 Household variables used in HRAM from CFM household survey data 62

3.6 Loan-level data calibration: $2005 \ldots$. . . . . . . . . . . 63

3.7 Loan-level data calibration: 2007 to 2008 . . . . . . . . . . . . . 64

3.8 Impacts of loosening policy from the structural model . . . . . . . . 68

3.9 Impact of interest rate shocks on arrears . . . . . . . . . . . . 72 


\section{List of Figures}

2.1 Effect of Winsorization on estimate of $\beta$ from equation (1) . . . . . 29

3.1 Amortization length and LTV for FTHBs . . . . . . . . . . . . 48

3.2 Average TDS and monthly PTI ratio for FTHBs . . . . . . . . . . . . 48

3.3 Impact of macroprudential loosening and tightening on credit growth 71 


\section{Chapter 1}

\section{Non-linear impacts of leverage on \\ firm growth}

\section{$1.1 \quad$ Introduction}

Does a firm's leverage choice impact the growth rates of its capital expenditures or employment in a non-linear manner? In a frictionless world, a firm's financing decision is irrelevant and has no impact on its future growth (Modigliani and Miller (1958)). However, asymmetric information and agency costs amongst shareholders, lenders, and managers imply that a firm's financing decision impacts its future growth. ${ }^{1}$ The empirical literature has found that the use of debt reduces a firms future growth and that the impact is larger for firms with weak growth opportunities relative to firms with favourable growth prospects. ${ }^{2}$ These studies assume the marginal impact of leverage on future growth is linear. In this paper I show that once non-linearities are included, the marginal impact of leverage for firms with similar growth prospects is higher for firms in higher leverage quartiles. I also show that the marginal impact

\footnotetext{
${ }^{1}$ Jensen and Meckling (1976) is the seminal paper discussing how a firms capital structure is influenced by agency costs. Stein (2003) provides a recent survey of the literature in this area.

${ }^{2}$ Empirical evidence can be found in Lang, Ofek, and Stulz (1996) and Aivazian, Ge, and Qiu (2005).
} 
of leverage for firms within the same leverage quartile is higher for firms with low growth opportunities. Overall, my results provide new evidence supporting the view that leverage acts as a drag on future growth and that the impact is larger for firms with weak growth prospects.

Negative relationships between leverage and firm growth are the result of agency conflicts or asymmetric information. A negative relationship between leverage and future growth may be the result of an agency conflict between shareholders and managers for firms with low growth opportunities (Jensen (1986) and Stulz (1990)). ${ }^{3}$ The idea is that managers tend to over-invest in non-profitable investments because their salaries are tied to firm size. The amount of internal funds available limits the extent to which managers can over-invest. As the firm takes on additional debt, there is less internal resources available to managers because debt carries with it an obligation to pay interest and principal. With less internal resources, managers are less able to over-invest. This use of debt to minimize the agency costs of over-investment implies a negative relationship between leverage and future growth, particularly for firms with few growth opportunities.

Asymmetric information can also give rise to a negative relationship between leverage and future growth. Using the costly state verification model developed in Townsend (1979), Bernanke, Gertler, and Gilchrist (1996) show that the cost of raising external debt is directly related to the leverage ratio of the firm. Firms with higher leverage ratios face a higher cost of borrowing funds due to an asymmetric information problem. Since lenders incur costs to verify the outcome of a project and that the outcomes of projects for firms with higher leverage need to be verified more often, the cost of external borrowing increases as a firm uses more leverage. This relationship between a firms' leverage ratio and cost of external funds imply that, irrespective of

\footnotetext{
${ }^{3}$ Myers (1977) shows that agency conflicts between shareholders and debt holders can give to a negative relationship between leverage and growth for firms in financial stress. Since I do not attempt to identify firms in financial distress, my results are not comparable to the debt overhang theory.
} 
future growth prospects, a firm with a higher leverage ratio will grow slower than a firm with a lower leverage ratio implying a negative relationship between leverage and future future growth.

The empirical literature has found support for the agency conflicts suggested by Jensen (1986) and Stulz (1990)), but not for the asymmetric information problem proposed by Townsend (1979). Lang, Ofek, and Stulz (1996) found that the impact of leverage on firm growth (i.e., investment and employment) is negatively related to leverage for large US manufacturing firms with low growth prospects, but not for firms with high growth prospects. These findings support the use of debt to mitigate the over-investment problem identified by (Jensen (1986) and Stulz (1990)). These results also imply that a firm with a higher leverage ratio and favourable growth prospects can grow faster than a firm with lower leverage but weak growth prospects providing evidence against the theory proposed by Townsend (1979).

For a large sample of Canadian firms across a variety of industries, Aivazian, Ge, and Qiu (2005) found that the impact of leverage negatively affects future investment for all firms regardless of growth opportunities, but the impact is larger for firms with weak growth opportunities. Thus, these findings also support the use of debt to reduce the agency conflict between managers and shareholders, but does not support the theory that, irrespective of growth prospects, firms with higher leverage ratios will grow slower than firms with lower leverage ratios.

A common feature of both sets of empirical results is that their methodologies assume that the impact of leverage on future growth is linear. My main contribution to this literature is to document that the impact is non-linear. ${ }^{4}$ To show my results are not country-specific, I demonstrate that the non-linear impacts are present for both US and Canadian companies. ${ }^{5}$ Another contribution is that I am the first to

\footnotetext{
${ }^{4}$ While I believe I am the first to analyze the non-linear impact of leverage on capital expenditure and employment growth at the firm level, the non-linear impact of leverage on firm survival has been studied by Huynh, Petrunia, and Voia (2010).

${ }^{5}$ Although results are broadly consistent across countries, some differences do emerge. I plan to
} 
analyze the impact of leverage on future employment growth, the 3 year growth rate of capital expenditures and the 3 year growth rate of employment for Canadian firms.

Since leverage can be an endogenous variable in investment regressions, Aivazian, Ge, and Qiu (2005) use the tangibility of assets as an instrumental variable. Another contribution of my paper is to extend their instrumental variable approach by using a broader set of instruments which have been shown by Frank and Goyal (2009) to consistently explain the leverage decisions of firms. These factors explain more of the variation in leverage than just tangibility of assets.

The remainder of this paper is organized as follows. Section 1.2 summarizes the data used in this paper. Empirical results from the capital structure regressions are discussed in section 1.3.1, results from the firm level growth regressions are discussed in 1.3.2. Section 1.4 concludes.

\section{$1.2 \quad$ Data}

The data I use in this report is taken from the Compustat database. This database contains annual financial statements, stock prices and levels of employment for active and inactive publicly traded companies across the world. I perform the following steps to arrive at my final samples of Canadian and US firms. First, I use the location of the firms headquarters to identify US and Canadian companies. Second, to screen out data entry errors, I drop observations where a firms total assets are missing, the year variable is missing or if two sets of financial statements were prepared for the same year. Third, I drop all firms that do not appear consecutively or that were involved in a merger or acquisition. ${ }^{6}$ The reason for dropping these firms is investigate the reasons for the differing results in future research.

${ }^{6}$ This procedure drops 541 observations due to mergers and 380 observations due to firms not appearing consecutively for the US sample. 61 observations are dropped due to mergers and 99 due to firms not appearing consecutively for the Canadian sample. Thus, any potential bias which may arise from this procedure is likely to be minimal given the relatively small number of firms which are dropped. 
that most of the variables I use are ratios comparing a variable at time $t$ with a variable at $t+1$. Thus, if a firms financial statements are missing for a year, it is not possible to construct these ratios. Mergers or acquisitions also make variables at time $t$ incomparable to a $t-1$ because the variable at $t-1$ is not revised to reflect the merger or acquisition at time $t$. Last, I drop all financial, insurance and real estate firms since these firms are regulated and their behavior is different from other firms in the sample. ${ }^{7}$ This initial data screening leaves unbalanced panel data sets comprised of approximately 277,000 observations for US companies and 38,400 observations for Canadian companies. There are approximately 20,500 unique US companies and 3,500 unique Canadian companies. Both data sets start in 1950 and end in 2016.

In this literature, book based, rather than market based, measures of leverage are used in the analysis. Book based leverage is the sum of the book values of short-term and long-term debt relative to the book value of total assets. In contrast, market based measures of leverage use the stock market's valuation of the firms stock price as an input to estimate the market value of assets. The stock market value of a firm contains financial market participants' views of future growth potential for a firm. Hence, if market based leverage were used to explain a firms future growth, a negative relationship would mechanically arise since a variable measuring the future growth of a company is being regressed on the inverse of financial market participants view of growth. ${ }^{8}$ Thus, the book value of leverage is used as an explanatory variable since it is not influenced by the current value of a companies stock price.

Although the book value of leverage does not contain financial market participants views of future growth, it may still be an endogenous variable due to management's inside information regarding the future growth prospects of the firm. This private

\footnotetext{
${ }^{7}$ These are firms with Standard Industrial Classification (SIC) codes between 6000 and 7000.

${ }^{8}$ This assumes that financial market participants tend to correctly assess the future growth of a firm.
} 
information could lead to either a positive or negative relationship between leverage and firm growth. A positive relationship between leverage and growth can be justified using the pecking order theory of Myers (1984). Suppose that managers, acting in the interest of shareholders, have private information that the firm has a large number of profitable investment opportunities but not enough internal funds to pay for them. In this case, external debt is preferred to external equity since the gains to debt holders are capped and all remaining profits go to the current shareholders. If the firms were to issue equity instead, all the gains would be shared with new shareholders, diluting the amount of profits going to current shareholders. As a result, a positive relationship between leverage and firm growth would be expected.

A negative relationship between leverage and firm growth can also be due to managers private information. In these cases, managers with current knowledge about future profitable investments may reduce leverage today so that they are not overly leveraged in the future, which would restrict their future ability to borrow to finance profitable investments. This strategic motive to reduce leverage prior to undertaking profitable investments in the future would result in a negative relationship between leverage and future capital expenditures.

Using capital structure regression to instrument for leverage avoids the potential endogeneity problem. In my first stage regressions, leverage is regressed on the industry median leverage ratio, the tangibility of assets, the market to book value of assets, firm size, profits,and year fixed effects. Frank and Goyal (2009) show that these variables have consistently explained the leverage decisions of firms over the 1950 to 2003 period. $^{9}$ Table 1.1 provides a list of variables I use in my first stage regression. The appendix provides more details describing the Compustat data used.

\footnotetext{
${ }^{9}$ These are the factors which consistently explain market based leverage. When considering book based leverage, Frank and Goyal (2009) note that for book leverage only median industry leverage, tangibility, profitability, and dividends consistently explain leverage. Nevertheless, I include all factors since, with the exception of market to book value for US firms, all are statistically significant in my first stage regressions. Also, I use year fixed effects rather than expected inflation since I do not have a long time series of expected inflation in Canada.
} 
Table 1.1: List of first stage regression variables

\begin{tabular}{ll}
\hline Lev & $\begin{array}{l}\text { Leverage is the sum of the book value of short-term and long-term } \\
\text { debt relative to total assets }\end{array}$ \\
IndLev & $\begin{array}{l}\text { Industry median leverage is the yearly median leverage ratio of firms } \\
\text { in the same four-digit industry }\end{array}$ \\
Tang & $\begin{array}{l}\text { Tangibility of assets is the sum of property plant and equipment relative } \\
\text { to total assets }\end{array}$ \\
Mktbk $\quad \begin{array}{l}\text { Market to book value of assets is the estimated market value of assets } \\
\text { relative to the book value of assets }\end{array}$ \\
Size $\quad$ Firm size is the logarithm of real total assets \\
Profit $\quad$ Profitability is operating income relative to total assets \\
Div $\quad$ Dividends takes the value of 1 if a dividend is paid, 0 otherwise.
\end{tabular}

My second stage regression model is the same panel fixed effects model used in Aivazian, Ge, and Qiu (2005). Table 1.2 lists the data used in the second stage regression. Variables which are used to measure firm growth are: investment, the growth of employment, the 3 year growth of investment and the 3 year growth of employment. These are the growth variables considered in Lang, Ofek, and Stulz (1996).

Table 1.2: List of second stage regression variables

\begin{tabular}{ll}
\hline Inv & $\begin{array}{l}\text { Investment is capital expenditures relative to lagged } \\
\text { property plant and equipment }\end{array}$ \\
Emp & The growth rate in the number of employees \\
3YR Inv & Three year growth rate of INV \\
3YR Emp & Three year growth rate of Emp \\
& $\begin{array}{l}\text { Earnings before extraordinary plus depreciation } \\
\text { Cash }\end{array}$ \\
& $\begin{array}{l}\text { Market to book value of assets is the estimated market value of assets } \\
\text { Mktbk }\end{array}$ \\
& Nelative to the book value of assets \\
Sales & Instrumented value for leverage \\
\hline Lev &
\end{tabular}


Cash flow and the market to book value of assets are typically used as regressors when estimating a firms future growth of capital expenditures. ${ }^{10}$ Firms with higher cash flows and better growth prospects tend to invest more than other firms. Sales in the previous year is included to control for the possibility that strong sales growth can also lead to increased capital expenditures.

Summary statistics for these variables are shown in Tables 1.3 and 1.4 for the US firms and Tables 1.5 and 1.6 for Canada. The tables document the number of observations, the mean, standard deviation, the minimum and maximum as well as various percentiles for each variable. Across both data sets, most of the variables contain extreme values. For instance, in the US data, the leverage ratio for the median firm and at the 95th percentile are 0.24 and 0.80 , respectively. Yet, the maximum leverage ratio is 5,319. A similar pattern is evident in the for other US variables and in the Canadian data as well. Such extreme values will have a large influence on results when performing linear regressions (Rousseeuw and Leroy (1987)). ${ }^{11}$ To minimize the influence of these extreme observations, I follow the common practice of Winsorizing the variables. ${ }^{12}$ That is, all values below the 5 th percentile are replaced with the observation at the 5th percentile. All observations above the 95th are replaced with the observation at the 95 th percentile. ${ }^{13}$

\footnotetext{
${ }^{10}$ For example see Fazzari, Hubbard, and Petersen (1988) and Kaplan and Zingales (1997).

${ }^{11}$ Estimation techniques less susceptible to extreme values such as quantile regressions could be used in place of linear regressions. However, to my knowledge, the theory and estimation of fixed effect quantile regressions remains in an early stage of development. For an early example see Koenker (2004).

${ }^{12}$ Unlike in my second chapter, I did not find any systematic relationship between investment and leverage when looking at the extreme values. Also, my results are unchanged if the extreme observations are removed from the data set.

${ }^{13}$ Results are similar for Winsorization thresholds between 2-5\% and 95-98\%.
} 
Table 1.3: Summary Statistics of US data used in the first stage regression

\begin{tabular}{l|ccccccc}
\hline stats & Lev & Ind & Tang & Mktbk & Profit & Size & Div \\
\hline $\mathrm{N}$ & 276,771 & 276,523 & 274,944 & 230,259 & 276,771 & 272,951 & 277,307 \\
mean & 0.78 & 0.24 & 0.32 & 14.43 & -0.66 & 4.43 & 0.47 \\
sd & 25.28 & 0.19 & 0.26 & 797.95 & 54.99 & 2.45 & 0.5 \\
min & -0.05 & 0 & 0 & -0.76 & $-23,957$ & -7.35 & 0 \\
p1 & 0 & 0 & 0 & 0.24 & -4.19 & -1.86 & 0 \\
p5 & 0 & 0.01 & 0.02 & 0.43 & -0.67 & 0.53 & 0 \\
p50 & 0.24 & 0.2 & 0.26 & 1.06 & 0.11 & 4.43 & 0 \\
p95 & 0.8 & 0.6 & 0.84 & 6.31 & 0.29 & 8.4 & 1 \\
p99 & 2.74 & 0.74 & 0.93 & 35.38 & 0.43 & 9.86 & 1 \\
max & 5,319 & 1.23 & 1.58 & 222,000 & 1,106 & 13.3 & 1 \\
\hline \multicolumn{7}{c}{ Notes: P in the tables refers to percentiles. }
\end{tabular}

Table 1.4: Summary Statistics of US data used in the second stage regression

\begin{tabular}{l|cccccc}
\hline & Inv & Emp & 3 YR Inv & 3 YR Emp & Cash & Sale \\
\hline $\mathrm{N}$ & 250,963 & 222,627 & 199,596 & 187,233 & 250,963 & 249,632 \\
mean & 0.84 & 0.27 & 4.04 & 0.73 & -5.4 & 13.08 \\
sd & 31.88 & 14.7 & 114.76 & 27.01 & 148.44 & 113.28 \\
min & -0.83 & -1 & -297 & -1 & $-20,168$ & -33.14 \\
p1 & 0 & -0.71 & -1 & -0.91 & -85.68 & 0 \\
p5 & 0 & -0.33 & -0.93 & -0.54 & -7.71 & 0.26 \\
p50 & 0.2 & 0.02 & 0.21 & 0.07 & 0.36 & 4.58 \\
p95 & 1.33 & 0.38 & 7.58 & 1.84 & 3.42 & 38.22 \\
p99 & 4.64 & 0.67 & 39.29 & 7.33 & 11.94 & 125.69 \\
max & $8,532.50$ & 5,665 & 27,222 & 9999 & 15,909 & 18,790 \\
\hline \multicolumn{7}{c}{ Notes: P in the tables refers to percentiles. }
\end{tabular}

Table 1.5: Summary Statistics of Canadian data used in the first stage regressions

\begin{tabular}{l|ccccccc}
\hline stats & Lev & Ind & Tang & Mktbk & Profit & Size & Div \\
\hline $\mathrm{N}$ & 38,355 & 38,420 & 38,315 & 35,344 & 38,355 & 38,042 & 38,425 \\
mean & 0.86 & 0.23 & 0.45 & 14.49 & -0.72 & 4.05 & 0.36 \\
sd & 16.62 & 3.19 & 0.31 & 631.24 & 17.13 & 2.62 & 0.48 \\
min & 0 & 0 & 0 & -0.16 & $-1,759$ & -7.35 & 0 \\
p1 & 0 & 0 & 0 & 0.15 & -9.85 & -3.34 & 0 \\
p5 & 0 & 0 & 0 & 0.35 & -1.3 & -0.41 & 0 \\
p50 & 0.16 & 0.14 & 0.43 & 1.05 & 0.06 & 4.15 & 0 \\
p95 & 0.71 & 0.49 & 0.94 & 7.97 & 0.26 & 8.16 & 1 \\
p99 & 4.44 & 0.71 & 0.98 & 45.87 & 0.4 & 9.62 & 1 \\
max & 1,277 & 362 & 1 & 69,892 & 109 & 11.3 & 1 \\
\hline
\end{tabular}

Notes: $\mathrm{P}$ in the tables refers to percentiles.

Table 1.6: Summary Statistics of Canadian data used in the second stage regressions

\begin{tabular}{l|cccccc}
\hline stats & Inv & Emp & 3 YR Inv & 3 YR Emp & Cash & Sale \\
\hline $\mathrm{N}$ & 33,664 & 16,389 & 25,750 & 12,340 & 33,664 & 33,061 \\
mean & 1.99 & 0.25 & 18.3 & 0.78 & -6.84 & 7.29 \\
sd & 82.57 & 5.99 & 80.3 & 15.77 & 180.03 & 100.56 \\
min & -7.13 & -1 & -217.5 & -1 & $-22,566$ & $-9,247$ \\
p1 & 0 & -0.78 & -1 & -0.95 & -136 & 0 \\
p5 & 0 & -0.37 & -1 & -0.61 & -10.6 & 0 \\
p50 & 0.18 & 0.01 & -0.93 & 0.07 & 0.17 & 1.21 \\
p95 & 1.53 & 0.75 & 11.25 & 2.02 & 2.1 & 23.97 \\
p99 & 6.89 & 3 & 100.6 & 883 & 10.28 & 92.08 \\
max & 10,458 & 622 & 95,433 & 1,182 & 10,561 & 13,908 \\
\hline \multicolumn{7}{c}{ Notes: P in the tables refers to percentiles. }
\end{tabular}




\subsection{Empirical Results}

\subsubsection{First Stage Capital Structure Regressions}

Since management's private information can make leverage an endogenous variable, I employ a two stage least squares approach. ${ }^{14}$ The instruments I use for leverage in the first stage are from Frank and Goyal (2009) and are displayed in 1.1. ${ }^{15}$

My first stage regressions take the following form:

$$
\begin{aligned}
\text { Lev }_{i, t} & =\alpha+\gamma_{t}+\beta_{1} \text { IndLev }_{i, t-1}+\beta_{2} \text { Tang }_{i, t-1}+\beta_{3} \text { Mktbk }_{i, t-1}+\beta_{4} \text { Profit }_{i, t-1} \\
& +\beta_{5} \text { Size }_{i, t-1}+\beta_{6} \text { Div }_{i, t}+\epsilon_{i, t}
\end{aligned}
$$

where the $\gamma_{t}$ 's represent year fixed effects which are included to capture shocks common to all firms.

Results are shown in Table 1.7 for both the US and Canadian firms. Results are broadly consistent across the two countries and are similar to the original Frank and Goyal (2009) findings. Firm level leverage is positively related to industry leverage, the amount of tangible assets owned, and the size of the firm. Firm-level leverage is negatively related to profitability and dividend payments. The market to book ratio is insignificant for the US firms but is significant for Canadian firms.

\footnotetext{
${ }^{14}$ Lamont (1997) provided an alternative method to eliminate the endogeneity problem. Since publicly traded firms typically have a main line of business and several smaller business segments, leverage proxies for managements inside information for the largest business segment and should not reflect the growth opportunities of smaller segments. Hence, firm level leverage is not endogenous when looking a future capital expenditures of smaller business segments. I do not follow this approach since I do not have access to business segment data.

${ }^{15}$ Rajan and Zingales (1995) is another widely cited paper and proposes a capital structure regression with four variables. I use the Frank and Goyal (2009) variables since they explain more of the variation in the data. The main reason for this finding is that Rajan and Zingales (1995) do not include industry effects. My results are unchanged if I drop the market-to-book value in this first stage regression.
} 
Table 1.7: First Stage Capital Structure Regressions

\begin{tabular}{l|cc}
\hline & US & Canada \\
\hline Industry & $0.646^{* * *}$ & $0.778^{* * *}$ \\
tang & $0.315^{* * *}$ & $0.049^{* * *}$ \\
mktbk & 0.000 & $0.004^{* * *}$ \\
profits & $-0.250^{* * *}$ & $-0.125^{* * *}$ \\
size & $0.009^{* * *}$ & $0.013^{* * *}$ \\
dividends & $-0.032^{* * *}$ & $-0.013^{* * *}$ \\
Year fixed effects & yes & yes \\
$R^{2}$ & 0.232 & 0.33 \\
$\mathrm{~N}$ & 211,131 & 31,755 \\
\hline
\end{tabular}

Notes: Standard errors are clustered at the firm and year level. *** denotes significance at the 0.01 level.

\subsubsection{Firm-level Growth Regressions}

Prior to investigating whether leverage has a non-linear impact on the future growth of a firm, I start by checking whether my data set and first stage regression lead to similar results found previously in the literature. To check for consistency with the literature, I first show that leverage tends to be negatively related to the future growth of a firm. I then show that the impact of leverage is higher for firms with low growth opportunities.

To show that leverage is negatively related to a firms future growth, I estimate the following:

$$
\begin{aligned}
y_{i, t} & =\alpha+\mu_{i}+\gamma_{t}+\lambda_{1} \text { Cash }_{i, t}+\lambda_{2} \text { Sale }_{i, t-1}+\lambda_{3} \text { Mktbk }_{i, t-1} \\
& +\beta_{1} L \widehat{E V_{i, t-1}}+\epsilon_{i, t}
\end{aligned}
$$

where $y_{i t}$ denotes either investment, the growth rate of employment, the three year growth rate of capital expenditures or the three year growth rate of employment. $\widehat{L E V_{i, t-1}}$ is the fitted values obtained from the various first stage regressions, the $\gamma_{t}$ 's are year fixed effects and the $\mu_{i}$ 's are firm fixed effects. Results from these regressions are shown in Table 1.8 for US firms and Table 1.9 for Canadian firms. 
Table 1.8: The impact of leverage on US firm growth

\begin{tabular}{l|cccc}
\hline & INV & Emp & 3Y INV & 3Y Emp \\
\hline Cash & 0.00 & $0.01^{* *}$ & $0.07^{* * *}$ & $0.04^{* * *}$ \\
Sales & $0.01^{* * *}$ & 0.00 & $0.01^{* * *}$ & $-0.01^{* * *}$ \\
Mktbk & $0.07^{* * *}$ & $0.05^{* * *}$ & $0.41^{* * *}$ & $0.12^{* * *}$ \\
$\widehat{L e v}$ & $-0.66^{* * *}$ & $-0.29^{* * *}$ & $-4.33^{* * *}$ & $-0.75^{* * *}$ \\
Year dummies & yes & yes & yes & yes \\
Firm dummies & yes & yes & yes & yes \\
$R^{2}$ within & 0.17 & 0.10 & 0.10 & 0.12 \\
$R^{2}$ between & 0.17 & 0.07 & 0.02 & 0.03 \\
$R^{2}$ overall & 0.19 & 0.08 & 0.06 & 0.07 \\
$\mathrm{~N}$ & 207,945 & 191,072 & 178,160 & 167,740 \\
\hline
\end{tabular}

Standard errors are clustered at the firm and year levels. ${ }^{* * *}$ denotes significance at the 0.01 level. ${ }^{* *}$ denotes significance at the 0.05 level.

Table 1.9: The impact of leverage on Canadian firm growth

\begin{tabular}{l|cccc}
\hline & INV & Emp & 3Y INV & 3Y Emp \\
\hline Cash & $-0.02^{* * *}$ & $0.01^{* * *}$ & $0.08^{* * *}$ & $0.04^{* * *}$ \\
Sales & $0.01^{* * *}$ & 0.00 & 0.00 & $-0.01^{* * *}$ \\
Mktbk & $0.08^{* * *}$ & $0.04^{* * *}$ & $0.54^{* * *}$ & $0.10^{* * *}$ \\
$\widehat{L e v}$ & $-0.58^{* * *}$ & $-0.25^{* * *}$ & $-3.56^{* * *}$ & $-0.30^{* * *}$ \\
Year dummies & yes & yes & yes & yes \\
Firm dummies & yes & yes & yes & yes \\
$R^{2}$ within & 0.17 & 0.08 & 0.10 & 0.09 \\
$R^{2}$ between & 0.10 & 0.03 & 0.04 & 0.01 \\
$R^{2}$ overall & 0.14 & 0.04 & 0.07 & 0.02 \\
$\mathrm{~N}$ & 30,422 & 14,902 & 24,153 & 11,557 \\
\hline
\end{tabular}

Standard errors are clustered at the firm and year levels. ${ }^{* * *}$ denotes significance at the 0.01 level. ${ }^{* *}$ denotes significance at the 0.05 level.

Findings are broadly consistent across the two countries. ${ }^{16}$ Leverage is found to have a significant negative relationship with a firms future growth for both US and Canadian firms. My US results, which are derived from firms across various industries, are consistent with the findings of Lang, Ofek, and Stulz (1996) which were based on large manufacturing firms, in that leverage has a negative impact on firm growth. For the Canadian firms, although, Aivazian, Ge, and Qiu (2005) showed

\footnotetext{
${ }^{16}$ The Cash variable is estimated to be negative for the Canadian sample of firms when explaining future capital expenditures which is uncommon in these regressions. I leave this issue for further research.
} 
leverage negatively impacts investment, I believe I am the first to report the negative impact of leverage on employment growth and the three year growth rates of capital expenditures and employment for Canada firms. Overall, my results are consistent with previous results in the literature and are also consistent with the theory that firms with higher leverage ratios should grow slower than firms with lower debt ratios. ${ }^{17}$

I now show that my data and first stage regressions also document that the impact of leverage of future growth is negative, but the impact is larger for firms with low growth opportunities. To show this result, I estimate the following equation:

$$
\begin{aligned}
y_{i, t} & =\alpha+\gamma_{t}+\mu_{i}+\lambda_{1} \text { Cash }_{i, t}+\lambda_{2} \text { Sale }_{i, t-1}+\lambda_{3} \text { Mktbk }_{i, t-1} \\
& +\beta_{1} L \widehat{E V_{i, t-1}}+\beta_{2} d_{2} \widehat{L E V_{i, t-1}}+\epsilon_{i, t}
\end{aligned}
$$

where $y_{i t}$ denotes either investment, the growth rate of employment, the three year growth rate of capital expenditures or the three year growth rate of employment.

In this specification, the reference group are those firms with weak growth prospects. A firm is labeled as having weak growth prospects if its market-to-book ratio (i.e., Tobin's Q) is below 1. $d_{2}$ takes the value of 1 if a firm has favorable growth prospects (i.e., market-to-book value greater than 1). Results from this specification are shown in table 1.10 for US firms and Table 1.11 for Canadian firms.

Again, results are consistent across countries and growth measures. Leverage reduces firm growth and the impact is larger for firms with weak growth opportunities. The results for the US companies differ somewhat from previous findings. Lang, Ofek, and Stulz (1996) found that for large manufacturing firms, the impact of leverage was negative for firms with low growth opportunities but had no impact for firms with high growth opportunities. My results, which are for firms across a variety of industries, suggests that leverage negatively impacts growth for all firms, but the impact is lower for higher growth firms.

\footnotetext{
${ }^{17}$ I leave the policy implications regarding the trade-offs associated with the benefits of debt (reducing agency costs) with the costs of debt (slower growth) for future research.
} 
Table 1.10: The impact of leverage on US firm growth for high and low growth firms

\begin{tabular}{l|cccc}
\hline & INV & Emp & 3 Y INV & 3Y Emp \\
\hline Cash & 0.00 & $0.01^{* *}$ & $0.07^{* * *}$ & $0.04^{* * *}$ \\
Sales & $0.01^{* * *}$ & 0.00 & $0.01^{* * *}$ & $-0.01^{* * *}$ \\
Mktbk & $0.07^{* * *}$ & $0.04^{* * *}$ & $0.41^{* * *}$ & $0.11^{* * *}$ \\
$\widehat{\text { Lev }}$ & $-0.72^{* * *}$ & $-0.34^{* * *}$ & $-1.85^{* * *}$ & $-0.91^{* * *}$ \\
$d_{2} \widehat{\mathrm{Lev}}$ & $0.12^{* * *}$ & $0.11^{* * *}$ & $1.24^{* * *}$ & $0.34^{* * *}$ \\
Year dummies & yes & yes & yes & yes \\
Firm dummies & yes & yes & yes & yes \\
$R^{2}$ within & 0.18 & 0.10 & 0.10 & 0.12 \\
$R^{2}$ between & 0.17 & 0.07 & 0.03 & 0.03 \\
$R^{2}$ overall & 0.19 & 0.08 & 0.06 & 0.07 \\
$\mathrm{~N}$ & 207,945 & 191,072 & 178,160 & 167,740 \\
\hline
\end{tabular}

Standard errors are clustered at the firm and year levels. $* * *$ denotes significance at the 0.01 level. $* *$ denotes significance at the 0.05 level.

Table 1.11: The impact of leverage on Canadian firm growth for high and low growth firms

\begin{tabular}{l|cccc}
\hline & INV & Emp & $3 \mathrm{Y} \mathrm{INV}$ & $3 \mathrm{Y}$ Emp \\
\hline Cash & $-0.02^{* * *}$ & $0.01^{* * *}$ & $0.08^{* * *}$ & $0.04^{* * *}$ \\
Sales & $0.01^{* * *}$ & 0.00 & 0.00 & $-0.01^{* * *}$ \\
Mktbk & $0.07^{* * *}$ & $0.04^{* * *}$ & $0.54^{* * *}$ & $0.11^{* * *}$ \\
$\widehat{\text { Lev }}$ & $-0.59^{* * *}$ & $-0.26^{* * *}$ & $-3.61^{* * *}$ & $-0.31^{* * *}$ \\
$d_{2} \widehat{\operatorname{Lev}}$ & $0.48^{* * *}$ & $0.23^{* * *}$ & $2.84^{* * *}$ & $0.29^{* * *}$ \\
Year dummies & yes & yes & yes & yes \\
Firm dummies & yes & yes & yes & yes \\
$R^{2}$ within & 0.18 & 0.08 & 0.10 & 0.09 \\
$R^{2}$ between & 0.11 & 0.03 & 0.04 & 0.01 \\
$R^{2}$ overall & 0.15 & 0.04 & 0.08 & 0.02 \\
$\mathrm{~N}$ & 30,422 & 14,902 & 24,153 & 11,557 \\
\hline
\end{tabular}

Standard errors are clustered at the firm and year levels. $* * *$ denotes significance at the 0.01 level. $* *$ denotes significance at the 0.05 level.

My results are consistent with Aivazian, Ge, and Qiu (2005) in that leverage negatively impacts future investment for all Canadian firms, but the impact is largest for low growth firms. I am the first to show that this result also applies for the other growth variables in the Canadian context.

Overall my results are consistent with the theory that debt is used to stop managers from over investing for low growth firms. These results provide evidence against 
the theory that a firms growth rate should be lower the higher its leverage ratio. Here, a firm with a high leverage ratio but favorable growth prospects are shown to have higher growth than firms with a lower leverage ratio but weaker growth prospects.

Up to this point, the impact of leverage on a firms future growth was assumed to be linear (abstracting from a firms growth potential). I now assess whether the impact of leverage is non-linear. To do this, I sort firms into four quartiles based on their leverage ratio. Within each leverage quartile, I split firms into two groups depending on their growth prospects (i.e., if their market to book ratio is greater than or less than 1).

To estimate whether the non-linear impacts of leverage on firm growth different for high and low growth firms I estimate the following:

$$
\begin{aligned}
y_{i, t} & =\alpha+\gamma_{t}+\mu_{i}+\lambda_{1} \operatorname{Cash}_{i, t}+\lambda_{2} \text { Sale }_{i, t-1}+\lambda_{3} \text { Mktbk }_{i, t-1} \\
& +\beta_{1} L \widehat{E V_{i, t-1}}+\beta_{2} d_{2} L \widehat{E V_{i, t-1}}+\beta_{3} d_{3} L \widehat{E V_{i, t-1}}+\beta_{4} d_{4} L \widehat{E V_{i, t-1}} \\
& +\beta_{5} d_{5} L \widehat{E V_{i, t-1}}+\beta_{6} d_{6} \widehat{L E V_{i, t-1}}+\beta_{7} d_{7} L \widehat{E V_{i, t-1}}+\beta_{8} d_{8} L \widehat{E V_{i, t-1}}+\epsilon_{i, t}
\end{aligned}
$$

where $y_{i t}$ denotes either investment, the growth rate of employment, the three year growth rate of capital expenditures or the three year growth rate of employment. $d_{2}$ takes the value of 1 if a firm is in the second leverage quartile and has weak growth prospects, $d_{3}$ represents firms in the third leverage quartile and has weak growth prospects, and $d_{4}$ is for firms in the highest leverage quartile and with weak growth prospects. $d_{5}$ takes the value of 1 if a firm is in the lowest leverage quartile and is a high growth firm. $d_{6}$ is for high growth firms in the second quartile of high leverage, etc.

Results for the US are shown in Table 1.12 and Table 1.13 for Canada. The estimates of the dummy variables in these tables represent the marginal impact of moving from one quartile group to another. Thus, for simplicity, the total estimated impact of leverage on a firms future growth is shown in Table 1.14 for US firms and 
1.15 for Canadian firms .

Table 1.12: The non-linear impact of leverage on US firm growth for high and low growth firms

\begin{tabular}{l|cccc}
\hline & INV & Emp & 3 Y INV & 3 Y Emp \\
\hline Cash & 0.00 & $0.02^{* *}$ & $0.08^{* * *}$ & $0.04^{* * *}$ \\
Sales & $0.01^{* * *}$ & 0.00 & $0.01^{* * *}$ & $-0.01^{* * *}$ \\
Mktbk & $0.07^{* * *}$ & $0.04^{* * *}$ & $0.36^{* * *}$ & $0.11^{* * *}$ \\
$\widehat{L e v}$ & $-0.42^{* * *}$ & $-0.14^{* * *}$ & $-3.57^{* * *}$ & $-0.97^{* * *}$ \\
$d_{2} \widehat{L e v}$ & $-0.15^{* * *}$ & $-0.10^{* * *}$ & $-0.42^{* * *}$ & $0.11^{* * *}$ \\
$d_{3} \widehat{L e v}$ & $-0.24^{* * *}$ & $-0.18^{* * *}$ & $-0.94^{* * *}$ & $0.17^{* * *}$ \\
$d_{4} \widehat{L e v}$ & $-0.33^{* * *}$ & $-0.25^{* * *}$ & $-1.52^{* * *}$ & $0.09^{* * *}$ \\
$d_{5} \widehat{L e v}$ & $0.22^{* * *}$ & $0.08^{* * *}$ & $1.42^{* * *}$ & $0.54^{* * *}$ \\
$d_{6} \widehat{L e v}$ & $0.14^{* * *}$ & $0.10^{* * *}$ & $1.14^{* * *}$ & $0.44^{* * *}$ \\
$d_{7} \widehat{L e v}$ & $0.15^{* * *}$ & $0.13^{* * *}$ & $1.45^{* * *}$ & $0.46^{* * *}$ \\
$d_{8} \widehat{L e v}$ & $0.07^{* * *}$ & $0.10^{* * *}$ & $1.05^{* * *}$ & $0.17^{* * *}$ \\
Year dummies & yes & yes & yes & yes \\
Firm dummies & yes & yes & yes & yes \\
$R^{2}$ within & 0.19 & 0.11 & 0.10 & 0.10 \\
$R^{2}$ between & 0.19 & 0.08 & 0.03 & 0.03 \\
$R^{2}$ overall & 0.20 & 0.08 & 0.06 & 0.06 \\
$\mathrm{~N}$ & 207,945 & 191,072 & 178,160 & 167,740 \\
\hline
\end{tabular}

Standard errors are clustered at the firm and year levels. ${ }^{* * *}$ denotes significance at the 0.01 level. ${ }^{* *}$ denotes significance at the 0.05 level.

These results, which are new to the literature, can be summarized as follows. Although there are exceptions, conditional on a firms growth prospects, the marginal impact of leverage on future growth tends to be larger (i.e., more negative) for firms with higher leverage ratios. Therefore, it is important to include non-linearities when assessing the impact of leverage on future growth. Also, conditional on the leverage quartile, the negative impact of leverage is larger for firms with low growth prospects. These findings are consistent across the US and Canadian firms. These findings tend to support the use of debt as a disciplining device for managers for firms with weak growth prospects. Further, these finding also provide evidence against the theory that, irrespective of growth opportunities, firms with higher leverage ratios should grow slower than firms with lower leverage ratios. 
Table 1.13: The non-linear impact of leverage on Canadian firm growth for high and low growth firms

\begin{tabular}{l|cccc}
\hline & INV & Emp & $3 Y$ INV & 3 Y Emp \\
\hline Cash & $-0.02^{* * *}$ & $0.01^{* * *}$ & $0.08^{* * *}$ & $0.04^{* * *}$ \\
Sales & $0.01^{* * *}$ & 0.00 & 0.00 & $-0.01^{* * *}$ \\
Mktbk & $0.07^{* * *}$ & $0.03^{* * *}$ & $0.46^{* * *}$ & $0.08^{* * *}$ \\
$\widehat{L e v}$ & $-0.60^{* * *}$ & $-0.16^{* * *}$ & $-5.27^{* * *}$ & $-0.81^{*}$ \\
$d_{2} \widehat{\operatorname{Lev}}$ & $-0.02^{* * *}$ & $-0.06^{* * *}$ & 2.16 & $0.47^{*}$ \\
$d_{3} \widehat{\operatorname{Lev}}$ & $-0.01^{* * *}$ & $-0.11^{* * *}$ & $1.87^{* * *}$ & $0.47^{*}$ \\
$d_{4} \widehat{\operatorname{Lev}}$ & $-0.03^{* * *}$ & $-0.17^{* * *}$ & 1.20 & 0.36 \\
$d_{5} \widehat{\operatorname{Lev}}$ & $0.64^{* * *}$ & $0.31^{* * *}$ & $5.56^{* * *}$ & $1.09^{* * *}$ \\
$d_{6} \widehat{\operatorname{Lev}}$ & $0.33^{* * *}$ & $0.29^{* * *}$ & $2.48^{* * *}$ & $0.80^{* * *}$ \\
$d_{7} \widehat{\operatorname{Lev}}$ & $0.17^{* * *}$ & $0.16^{* * *}$ & $1.48^{* * *}$ & $0.58^{* * *}$ \\
$d_{8} \widehat{\operatorname{Lev}}$ & $0.09^{* * *}$ & $0.13^{* * *}$ & $1.10^{* * *}$ & $0.28^{* * *}$ \\
Year dummies & yes & yes & yes & yes \\
Firm dummies & yes & yes & yes & yes \\
$R^{2}$ within & 0.18 & 0.08 & 0.10 & 0.10 \\
$R^{2}$ between & 0.11 & 0.04 & 0.04 & 0.03 \\
$R^{2}$ overall & 0.15 & 0.05 & 0.07 & 0.06 \\
$\mathrm{~N}$ & 30,422 & 14,902 & 24,153 & 11,557 \\
\hline
\end{tabular}

Standard errors are clustered at the firm and year levels. *** denotes significance at the 0.01 level. $* *$ denotes significance at the 0.05 level.

Table 1.14: Non-linear impacts of leverage on future growth US Firms by leverage quartile

\begin{tabular}{l|cc|cc|cc|cc}
\hline Quantile Range & \multicolumn{2}{|c|}{ Inv } & \multicolumn{2}{c}{ Emp } & \multicolumn{2}{c}{ 3YR Inv } & \multicolumn{2}{c}{ 3YR Emp } \\
& $q<1$ & $q>1$ & $q<1$ & $q>1$ & $q<1$ & $q>1$ & $q<1$ & $q>1$ \\
$0.00-0.06$ & -0.42 & -0.20 & -0.14 & -0.06 & -3.57 & -2.51 & -0.97 & -0.43 \\
$0.06-0.24$ & -0.57 & -0.28 & -0.24 & -0.04 & -3.99 & -2.43 & -0.86 & -0.53 \\
$0.24-0.41$ & -0.68 & -0.27 & -0.32 & -0.01 & -4.51 & -2.12 & -0.80 & -0.51 \\
$0.41-0.80$ & -0.75 & -0.35 & -0.39 & -0.04 & -5.09 & -2.52 & -0.89 & -0.80 \\
\hline
\end{tabular}

Table 1.15: Non-linear impacts of leverage on future growth Canadian Firms by leverage quartiles

\begin{tabular}{l|cc|cc|cc|cc}
\hline Quantile Range & \multicolumn{2}{|c|}{ Inv } & \multicolumn{2}{c}{ Emp } & \multicolumn{2}{c}{3 Y Inv } & \multicolumn{2}{c}{ 3YR Emp } \\
& $q<1$ & $q>1$ & $q<1$ & $q>1$ & $q<1$ & $q>1$ & $q<1$ & $q>1$ \\
$0.00-0.00$ & -0.60 & 0.04 & -0.16 & 0.15 & -5.27 & 0.29 & -0.81 & 0.28 \\
$0.06-0.16$ & -0.62 & -0.27 & -0.22 & 0.13 & -5.27 & -2.79 & -0.34 & -0.01 \\
$0.16-0.34$ & -0.61 & -0.43 & -0.27 & 0 & -3.40 & -3.79 & -0.34 & -0.26 \\
$0.34-0.71$ & -0.63 & -0.51 & -0.33 & -0.03 & -5.27 & -4.17 & -0.81 & -0.81 \\
\hline
\end{tabular}




\subsubsection{Robustness Check}

A concern when assessing the impact of leverage on the future growth of the firm is that the results may be capturing industry effects. That is, there may be some industries which may naturally have increasing leverage ratios and declining growth rates. To check the robustness of my results to industry effects, for each firm-level variable in the regressions, I subtract the industry yearly median value. Results from these regressions are shown in Table 1.16 for US firms and 1.17 for Canadian firms. Again, the estimates of the dummy variables in these tables represent the marginal impact of moving from one quartile group to another. Thus, the total estimated impact of leverage on a firms future growth is shown in Table 1.18 for US firms and 1.19 for Canadian firms .

The results from using the industry adjusted variables are similar to my previous results. For the most part, the impact of leverage on a firms future growth tends to be larger (and more negative) for firms with higher leverage ratios. Also, the impact

of leverage on future growth tends to be larger and more negative for firms with low growth opportunities. 
Table 1.16: The non-linear impact of leverage on US firm growth for high and low growth firms controlling for industry effects

\begin{tabular}{l|cccc}
\hline & INV & Emp & $3 \mathrm{Y}$ INV & $3 \mathrm{Y}$ Emp \\
\hline Cash & $-0.003^{*}$ & $0.01^{* *}$ & $0.06^{* * *}$ & $0.03^{* * *}$ \\
Sales & $0.01^{* * *}$ & 0.00 & $0.01^{* * *}$ & $-0.004^{* * *}$ \\
Mktbk & $0.07^{* * *}$ & $0.04^{* * *}$ & $0.34^{* * *}$ & $0.11^{* * *}$ \\
$\widehat{\text { Lev }}$ & $-0.62^{* * *}$ & $-0.24^{* * *}$ & $-4.51^{* * *}$ & $-0.92^{* * *}$ \\
$d_{2} \widehat{\operatorname{Lev}}$ & $-0.10^{* * *}$ & $0.07^{* *}$ & $0.57^{*}$ & 0.03 \\
$d_{3} \widehat{\mathrm{Lev}}$ & $-0.10^{* *}$ & $-0.12^{* * *}$ & $-0.09^{* * *}$ & -0.13 \\
$d_{4} \widehat{\operatorname{Lev}}$ & $-0.39^{* * *}$ & $-0.36^{* * *}$ & $-2.24^{* * *}$ & -0.43 \\
$d_{5} \widehat{\operatorname{Lev}}$ & $0.19^{* * *}$ & $0.11^{* * *}$ & $1.80^{* * *}$ & $0.41^{* * *}$ \\
$d_{6} \widehat{\operatorname{Lev}}$ & $0.08^{* *}$ & 0.00 & $1.69^{* * *}$ & $0.42^{* * *}$ \\
$d_{7} \widehat{\operatorname{Lev}}$ & 0.00 & 0.00 & $1.83^{* * *}$ & $0.48^{* * *}$ \\
$d_{8} \widehat{\operatorname{Lev}}$ & $0.02^{* * *}$ & $0.17^{* * *}$ & $1.30^{* * *}$ & $0.28^{* * *}$ \\
Year dummies & yes & yes & yes & yes \\
Firm dummies & yes & yes & yes & yes \\
$R^{2}$ within & 0.14 & 0.06 & 0.08 & 0.07 \\
$R^{2}$ between & 0.17 & 0.04 & 0.01 & 0.01 \\
$R^{2}$ overall & 0.11 & 0.05 & 0.04 & 0.04 \\
$\mathrm{~N}$ & 207,945 & 191,072 & 178,160 & 167,740 \\
\hline
\end{tabular}

Standard errors are clustered at the firm and year levels. ${ }^{* * *}$ denotes significance at the 0.01 level. ${ }^{* *}$ denotes significance at the 0.05 level. 
Table 1.17: The non-linear impact of leverage on Canadian firm growth for high and low growth firms controlling for industry effects

\begin{tabular}{l|cccc}
\hline & INV & Emp & 3 Y INV & 3 Y Emp \\
\hline Cash & $-0.02^{* * *}$ & $0.004^{* * *}$ & $0.07^{* * *}$ & $0.02^{* *}$ \\
Sales & $0.01^{* * *}$ & 0.00 & 0.00 & $-0.003^{*}$ \\
Mktbk & $0.06^{* * *}$ & $0.02^{* * *}$ & $0.32^{* * *}$ & $0.03^{* * *}$ \\
$\widehat{L e v}$ & $-0.53^{* * *}$ & $-0.05^{* * *}$ & $-7.41^{* * *}$ & $-0.448^{*}$ \\
$d_{2} \widehat{L e v}$ & $-0.18^{* * *}$ & $-0.28^{* *}$ & 1.38 & -0.22 \\
$d_{3} \widehat{L e v}$ & $-0.56^{* * *}$ & $-0.32^{*}$ & -2.22 & -0.48 \\
$d_{4} \widehat{L e v}$ & $-0.73^{* * *}$ & $-0.71^{* * *}$ & -3.72 & -0.61 \\
$d_{5} \widehat{L e v}$ & $0.47^{* * *}$ & $0.32^{* *}$ & $11.80^{* * *}$ & 0.59 \\
$d_{6} \widehat{\operatorname{Lev}}$ & $0.30^{* * *}$ & $0.18^{* *}$ & $6.38^{* * *}$ & $0.69^{* * *}$ \\
$d_{7} \widehat{\operatorname{Lev}}$ & $0.30^{* *}$ & $0.37^{* *}$ & $10.22^{* * *}$ & $1.57^{* * *}$ \\
$d_{8} \widehat{\operatorname{Lev}}$ & 0.01 & $0.49^{* * *}$ & $5.91^{* * *}$ & $0.67^{* *}$ \\
Year dummies & yes & yes & yes & yes \\
Firm dummies & yes & yes & yes & yes \\
$R^{2}$ within & 0.11 & 0.03 & 0.08 & 0.03 \\
$R^{2}$ between & 0.05 & 0.01 & 0.03 & 0.01 \\
$R^{2}$ overall & 0.08 & 0.01 & 0.04 & 0.01 \\
$\mathrm{~N}$ & 30,422 & 14,902 & 24,153 & 11,557 \\
\hline
\end{tabular}

Standard errors are clustered at the firm and year levels. $* * *$ denotes significance at the 0.01 level. ** denotes significance at the 0.05 level.

Table 1.18: Non-linear impacts of leverage on future growth of US firms by leverage quartile industry adjusted

\begin{tabular}{l|cc|cc|cc|cc}
\hline Quantile Range & \multicolumn{2}{|c|}{ Inv } & \multicolumn{2}{c}{ Emp } & \multicolumn{2}{c}{ 3YR Inv } & \multicolumn{2}{c}{ 3YR Emp } \\
& $q<1$ & $q>1$ & $q<1$ & $q>1$ & $q<1$ & $q>1$ & $q<1$ & $q>1$ \\
$-0.80--0.08$ & -0.62 & -0.43 & -0.24 & -0.13 & -4.51 & -2.71 & -0.92 & -0.51 \\
$-0.08-0.00$ & -0.72 & -0.54 & -0.17 & -0.24 & -3.94 & -2.82 & -0.92 & -0.52 \\
$0.00-0.12$ & -0.72 & -0.62 & -0.36 & -0.24 & -4.60 & -2.68 & -0.92 & -0.44 \\
$0.08-0.80$ & -1.01 & -0.60 & -0.60 & -0.07 & -6.75 & -3.21 & -1.35 & -0.64 \\
\hline
\end{tabular}

Table 1.19: Non-linear impacts of leverage on future growth of Canadian firms by leverage quartiles

\begin{tabular}{l|cc|cc|cc|cc}
\hline Quantile Range & \multicolumn{2}{|c|}{ Inv } & \multicolumn{2}{c}{ Emp } & \multicolumn{3}{c}{ 3YR Inv } & \multicolumn{2}{c}{ 3YR Emp } \\
& $q<1$ & $q>1$ & $q<1$ & $q>1$ & $q<1$ & $q>1$ & $q<1$ & $q>1$ \\
$-0.71--0.02$ & -0.53 & -0.06 & -0.05 & 0.27 & -7.41 & 4.39 & -0.45 & -0.45 \\
$-0.02-0.00$ & -0.71 & -0.23 & -0.33 & 0.13 & -7.41 & -1.03 & -0.45 & 0.14 \\
$0.00-0.08$ & -1.09 & -0.23 & -0.37 & 0.32 & -7.41 & 2.81 & -0.45 & 1.12 \\
$0.08-0.71$ & -1.26 & -0.53 & -0.76 & 0.44 & -11.13 & -1.50 & -0.45 & 0.22 \\
\hline
\end{tabular}




\subsection{Conclusion}

In this paper I have shown that the marginal impact of leverage on future growth tends to be larger for more highly leveraged firms both in the US and Canada. Therefore, it is important to take non-linearities into account when assessing the impact of leverage on future growth. I have also shown that the negative impact of leverage tends to be larger for firms with low growth prospects. Overall, my results provide new evidence supporting the use of debt as a way to restrict managers from over-investing in unprofitable investments at the expense of current shareholders. In addition, my findings also provide evidence against the theory that irrespective of growth opportunities, firms with higher leverage ratios should growth slower than firms with lower leverage ratios.

There are two methodological changes I hope to consider in future research. First, I have arbitrarily imposed thresholds values using quartiles to identify highly leveraged firms and then analyzed how leverage impacted the firms future growth. A complementary way to study non-linearities could be to estimate, rather than exogenously select, the leverage thresholds. For example, is there a certain leverage threshold that once crossed, a firms investment falls much more rapidly compared to firms below the threshold? A second methodological change would be to estimate quantile panel regressions to estimate the impact of leverage on different tails of a firms future growth. For instance, the impact of leverage on future capital expenditures could be very different for firms with very high investment rates relative to firms with low investment rates. I hope to tackle these two issues in future research. 


\subsection{Data Appendix}

Variables used from Frank and Goyal (2009) are (text is taken directly from Frank and Goyal (2009)):

- $L E V_{i, t}$ is given by total debt divided by the book value of assets

- INDLEV $V_{i, t-1}$ is the median of total debt to market value of assets by SIC code and by year. Industry is defined at the four digit SIC code level.

- Tang $_{i, t-1}$ is the ratio of net property, plant, and equipment to assets.

- $M k t b k_{i, t-1}$ is the ratio of MVA to assets. MVA is obtained as the sum of the market value of equity + short-term debt long-term debt + preferred-liquidation value - deferred taxes and investment tax credit.

- Profit $t_{i, t-1}$ is operating income before depreciation to assets.

- Assets is the log of assets deflated to 1992 dollars using the GDP deflator.

- Dividends is a dummy variable that takes the value of 1 if firms paid a dividend last year.

Variables from Aivazian, Ge, and Qiu (2005) are (text taken directly from Aivazian, Ge, and Qiu (2005):

- $I_{i, t}$ is net investment - depreciation to lagged net fixed assets (property plant and equipment).

- $L E V_{i, t-1}$ same as Frank and Goyal (2009)

- $C F_{i, t-1}$ earnings before extraordinary items plus depreciation

- $Q$ is same as Frank and Goyal (2009).

- $S A L E_{i, t-1}$ is Net Sales divided by lagged net fixed assets. 


\section{Chapter 2}

\section{Do real estate shocks affect corporate investment?}

\section{$2.1 \quad$ Introduction}

In "The Collateral Channel: How Real Estate Shocks Affect Corporate Investment", Chaney, Sraer, and Thesmar (2012) - henceforth, CST - study how changes in the value of real estate a firm owns affects its level of investment. They find that over the 1993-2007 period, a $\$ 1$ increase in collateral (the value of real estate a firm actually owns) leads the representative US public corporation to raise its investment by 6 cents $(\$ 0.06)$. CST emphasize the economic significance of this sensitivity as real estate represents a sizeable fraction of the tangible assets that firms hold on their balance sheet.

In this note, we first replicate their findings by combining their submitted data and software provided on the American Economic Review's website with the required Compustat Data. We then show their findings on the collateral channel are highly sensitive to the Winsorization threshold chosen prior to the empirical analysis. As the Winsorization threshold increases, the estimated sensitivity to investment to real 
estate shocks increases. When the threshold is $0 \%$ (i.e., using the unaltered data), the point estimate is close to zero suggesting that real estate shocks do not affect corporate investment. The point estimate is as high as 6 cents only if the data is Winsorized using a 5\% threshold level. Winsorization is, therefore, necessary for evidence favourable to the collateral channel. We discuss potential reasons for this sensitivity. As a final contribution, this paper shows that the identification based on local variations in real estate prices does not provide evidence on the collateral channel.

\subsection{Winsorization}

The practice of Winsorization is commonly and widely used in a variety of applied econometric contexts in finance and labour economics studies to 'clean the data'. ${ }^{1}$ Winsorizing reduces values at the low and high ends of the sorted data to a predetermined cut-off point. As discussed in Bollinger and Chandra (2005), however, Winsorizing data can induce or exacerbate biases in estimation. We demonstrate that this problem is severe for CST's finding: their main result (6 cents increase in investment per $\$ 1$ increase in the value of real estate the firm owns) is obtained only if the data is Winsorized. Recently, in the 2017 Presidential Address to the American Financial Association, Harvey (2017) has drawn attention to this form of data exclusion, among other choices made in applied work. He writes: Researchers make many choices in terms of standardization, log or other transformations, winsorization, and outlier exclusion. If these choices lead to the most significant results being presented, this is p-hacking. We view our findings as an example of how Winsorization can have serious implications when determining the importance of the collateral channel. The extent to which real estate shocks affect corporate investment, therefore, remains an

\footnotetext{
${ }^{1}$ See, for example, Angrist and Krueger (2000), Harvey (2017), among others. Tukey (1962) coined the term Winsorizing or Winsorization in honour of Charles P. Winsor.
} 
open question for further research.

\subsection{Replication}

In this section we discuss the econometric model and data used in CST and replicate their results. The main empirical specification from CST (throughout we use same notation as in their paper) is

$$
I N V_{i t}^{l}=\alpha_{i}+\delta_{t}+\beta R E \text { Value }_{i t}+\gamma P_{t}^{l}+\text { controls }_{i t}+\epsilon_{i t}
$$

where $I N V_{i t}^{l}$ is investment by firm $i$ at time $t$ located in the Metropolitan Statistical Area (MSA) $l$. Parameters $\alpha_{i}$ are firm fixed effects and $\delta_{t}$ are time dummy variables designed to capture macroeconomic fluctuations in real estate prices. The variable $R E$ Value $_{i t}$ measures the market value of real estate assets owned by firm $i$ at time $t$. Due to data limitations, it is assumed that all real estate owned by a firm is located in MSA $l . P_{t}^{l}$ measures real estate prices at time $t$ in area $l$, and controls $s_{i t}$ include the amount of cash on the balance sheet, the previous year's ratio of the market-to-book value of equity, and the interaction of real estate prices with controls for ownership of real estate assets (i.e., quintile of firm age, return on assets, firm size measured by the total amount of assets, industry dummy and state dummy). ${ }^{2}$ All variables except market value of equity to book value of equity are normalized by past year's Property Plant and Equipment (PPE).

Parameter $\beta$ in (2.1) is the coefficient of interest in CST's empirical analysis since it captures the sensitivity of investment to changes in real estate value the firm actually owns. ${ }^{3}$

\footnotetext{
${ }^{2}$ We use the data and programs available for the CST paper on the American Economic Review webpage. In addition, we downloaded firm level financial data from COMPUSTAT via WRDS and followed instructions from the readme file to merge this data with what is available on the American Economic Review webpage.

${ }^{3}$ Due to data limitations, CST are only able to measure the real estate holdings of a firm in 1993,
} 
Since real estate prices, and hence the value of real estate owned by a firm, are likely correlated with its investment opportunities, CST use the Instrumental Variables (IV) approach. They use the following first-stage specification

$$
P_{t}^{l}=\alpha^{l}+\delta_{t}+\gamma E^{l} \times I R_{t}+u_{t}^{l}
$$

where $\alpha^{l}$ are MSA level fixed effects, $\delta_{t}$ are time dummy variables. $E^{l}$ are the housing supply elasticities developed in Saiz (2010), and $I R_{t}$ is the nationwide real interest rate at which banks refinance their home loans at time $t .{ }^{4}$ CST use two sets of MSA level real estate prices in their analysis: office prices and residential prices. All of our results use residential prices since they are publicly available. We do not have access to the office price index. Nevertheless, as mentioned by CST, results are similar regardless of price index used.

The firm level financial data is obtained from Compustat. CST apply an initial selection criteria to this data:

We keep firms whose headquarters are located in the United States and exclude from the sample firms operating in the finance, insurance, real estate, construction, and mining industries, as well as firms involved in a major takeover operation. We require firms to have available data every consecutive year they appear in the sample. We keep only firms that appear at least three consecutive years in the sample. CST p. 2383-2384.

which we denote by $Q_{i, 1993}$. To measure the value of real estate holdings, CST inflate $Q_{i, 1993}$ by MSA level real estate prices, $P_{t}^{l}$, and then normalize by $P P E_{i, t-1}$. Thus, RE Value $i t \equiv \frac{Q_{i, 1993 * P_{t}^{l}}}{P P E_{i, t-1}}$. Therefore, the sensitivity of investment to real estate shocks is given by: $\frac{\partial I N V_{i t}^{l}}{\partial P_{t}^{l}}=\left[\beta * \frac{Q_{i, 1993}}{P P E_{i, t-1}}+\gamma\right]$. Since the focus of this note is on replication, we leave the interpretation issue of $\beta$ aside.

${ }^{4}$ Davidoff (2016) shows that the interaction of housing supply elasticities and the nationwide interest rate is not a valid instrument for real estate prices. Nevertheless, in addition to replicating CST's results, the main purpose of our note is to highlight the sensitivity of CST's results to arbitrary Winsorization thresholds. As we show in our note, the Winsorization process biases the unaltered data in favour of finding evidence of the collateral channel. This bias remains regardless of the choice of the instrumental variable used. 
We do the same and refer to the data obtained after this initial selection criteria as the 'unaltered data' (no Winsorization).

The final step CST perform prior to estimation is to Winsorize the unaltered data. In general, Winsorization replaces extreme values at the low and high ends of the sorted data to arbitrarily chosen cut-off points. For instance, if a $5 \%$ threshold is used, the bottom $5 \%$ of observations are replaced with the value corresponding to the 5th percentile and those above the 95th percentile are replaced with the value corresponding to the 95th percentile.

We apply the same Winsorization thresholds as in CST:

Finally, to ensure that our results are statistically robust, all variables defined as ratios are windsorized using as thresholds the median plus/minus five times the interquartile range.... Our results are unchanged if we use this 5 percent windsorizing methods for all variables (footnote 10). CST, p. 2386

The second and third columns in Table 2.1 displays CST's reported results using office prices and residential real estate prices, respectively. Column 4 shows our replication of their residential real estate price result using OLS and column 5 shows the IV results. As evident, both our OLS and IV based replication of the results are very similar to the CST results. A $\$ 1$ increase in collateral (the value of real estate a firm actually owns) leads the representative US public corporation to raise its investment by approximately 6 cents $(\$ 0.06)$. 


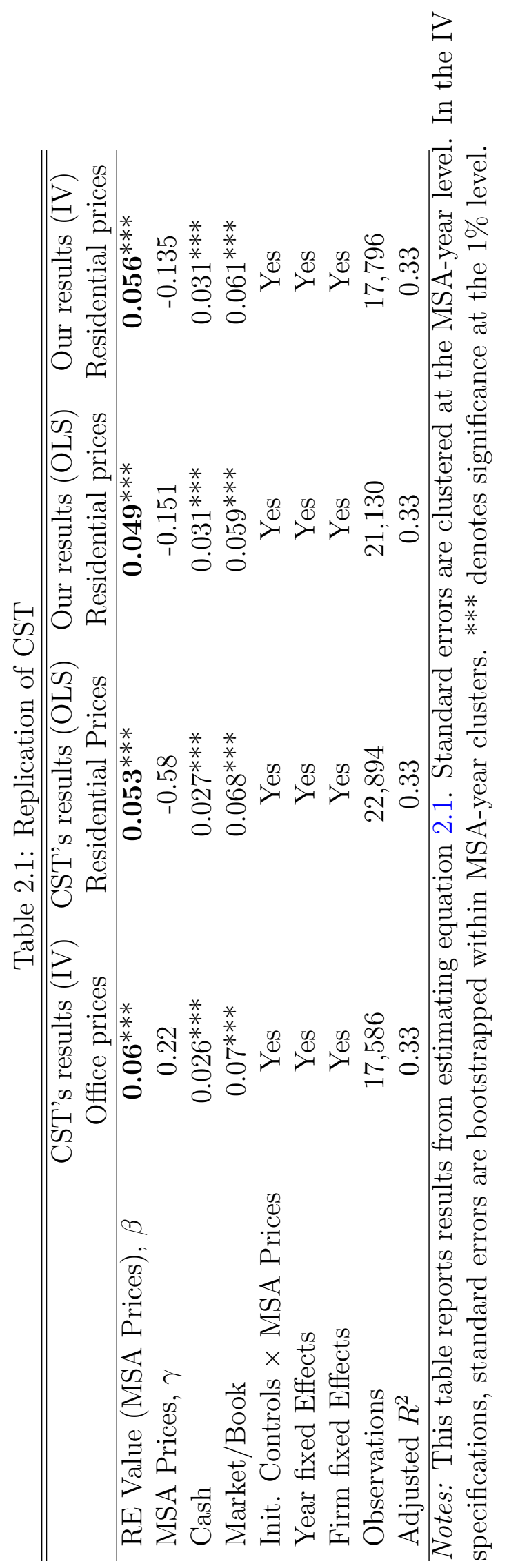




\subsection{The Effect of Winsorization}

In this section, we demonstrate that CST's results are quite sensitive to arbitrarily chosen Winsorization thresholds. Figure 2.1 plots OLS estimates of $\beta$ from (2.1) when we apply the Winsorization threshold to the data incrementally increasing from $0 \%$ upto a threshold of $5 \% .^{5}$ As evident, the choice of Winsorization threshold has a large impact on the estimate of $\beta$. When the threshold is $0 \%$ (i.e., using the unaltered data), the point estimate is close to zero suggesting that real estate shocks do not affect corporate investment. As the Winsorization threshold is increased, the sensitivity of investment to real estate shocks also increases and becomes statistically and economically meaningful.

Figure 2.1: Effect of Winsorization on estimate of $\beta$ from equation (1)

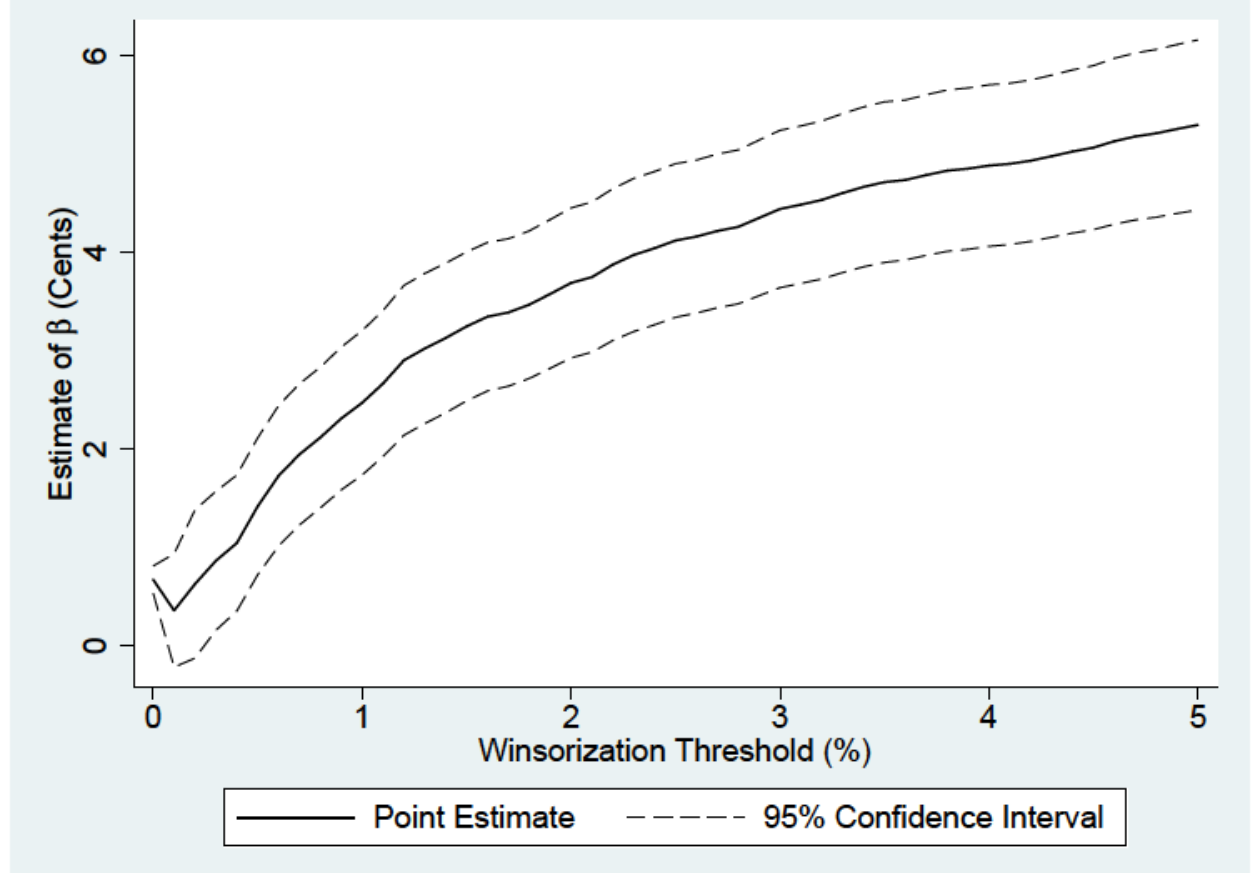

As noted in Angrist and Krueger (2000), Winsorizing the original data is performed when it is believed that the extreme values "are exaggerated versions of the true values, but the true values belong in the tails". In Table 2.2 we document

\footnotetext{
${ }^{5}$ Similar results are obtained if IV is used rather than OLS.
} 
the smallest and largest extreme values in the unaltered data (no Winsorization). There is little difference between the 1st percentile and the smallest observations for investment and REValues. Large differences are evident at the higher end of the distributions. For instance, the 99th percentile for investment takes the value of 3.478, yet the largest observation takes the value 1,226.833. The data for REValues also contain extreme values. While Table 2.2 shows the smallest and largest extreme values, a general feature of the unaltered data is that there are a continuum of increasing values just beyond the 99th percentile with only a minor number of extreme values far away from the rest of the unaltered data.

Table 2.2: Summary Statistics for $I N V_{i t}$ and $R E V_{a l u e}$

\begin{tabular}{lcc|ccc}
\hline \hline Percentile & $I N V_{i t}$ & RE Value $_{i t}$ & Examples of Extreme Values & $I N V_{i t}$ & RE Value $_{i t}$ \\
\hline 1 & 0 & 0 & & -0.288 & 0 \\
5 & 0.025 & 0 & 4 Smallest Observations & -0.088 & 0 \\
10 & 0.051 & 0 & -0.058 & 0 \\
25 & 0.112 & 0 & & -0.055 & 0 \\
50 & 0.207 & 0.202 & & & \\
75 & 0.400 & 1.063 & & 448 & 37,259 \\
90 & 0.782 & 2.460 & & 4,952 & 64,450 \\
95 & 1.121 & 4.226 & & 1,056 & 66,633 \\
99 & 3.478 & 19.721 & & 1,227 & 169,462 \\
\hline
\end{tabular}

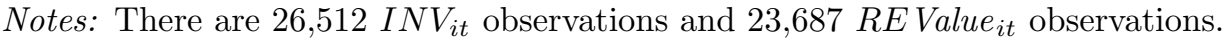

Estimating (2.1) including all extreme values (e.g., those above the 95th percentile) may exert a large influence on the parameter estimate, and could be either supportive or go against the maintained hypothesis. Normally, one finds evidence in the unaltered data (no Winsorization) and then check robustness to the extreme values (e.g., Kaplan and Zingales (1997)). In the CST case, however, it is the other way round. Estimating (2.1) without Winsorization goes against the maintained hypothesis and we obtain the close to zero cents result (Figure 2.1).

Extreme observations can be highly informative about the particular theory or channel that one wishes to understand or find evidence for. So a natural question that arises here is: What do the extreme observations represent? We now turn to 
investigating this question in greater detail.

\subsubsection{Do Extreme Values Represent Firms Without Collat- eral Constraints?}

An important feature of the unaltered data is that the vast majority of firms with very high investment rates do not own any real estate. Thus, extreme investment values likely represent firms without collateral constraints. Winsorization substantially reduces the influence of these observations which biases the estimation result in favour of finding evidence for the collateral channel. Table 2.3 confirms this point. The first two columns show the quartile and quartile ranges of the unadjusted REValue for all firms in the dataset. The third and fourth columns show that $92 \%$ of firms which have their investment Winsorized by CST (i.e., the high investing firms) fall into the lowest quartile of real estate holders. These high investing firms in the bottom quartile of real estate holding firms own no real estate assets. This finding also provides the reason why the point estimate in Figure 2.1 increases as the Winsorization threshold increases. Detecting the presence of the collateral channel requires a positive relationship between a firm's real estate values and investment. Firms with very high investment rates and no real estate holdings weaken this link. Because the Winsorization process minimizes the influence of these high-investing and no-real-estate-holdings firms, the point estimate increases.

Table 2.3: Real Estate holdings of high investing firms

\begin{tabular}{|c|c|c|c|}
\hline $\begin{array}{l}\text { RE } \text { Value }_{i t} \\
\text { Quartile }\end{array}$ & $\begin{array}{l}R E \text { Value }_{i t} \\
\text { Range }\end{array}$ & $\begin{array}{l}\text { \# of firms with } \\
\text { investment Winsorized }\end{array}$ & $\begin{array}{c}\% \text { of firms with } \\
\text { investment Winsorized }\end{array}$ \\
\hline 1 & $0-0$ & 679 & 91.76 \\
\hline 2 & $0.002-0.202$ & 5 & 0.68 \\
\hline 3 & $0.202-1.063$ & 10 & 1.35 \\
\hline 4 & $1.063-169,461.600$ & 46 & 6.22 \\
\hline Total & & 740 & 100 \\
\hline
\end{tabular}




\subsubsection{Are Extreme Values Data Errors?}

One potential reason for an extreme value in the data could be that it is simply a data error. This is often viewed as a justification for either dropping the extreme value or adopting Winsorization. It is possible to check whether the extreme values are correctly captured by Compustat because publicly traded firms are required to submit their financial statements to the Securities and Exchange Commission. ${ }^{6}$ While a manual verification of all data points is unfeasible, we nevertheless manually check the 10 largest investment observations. We verified that 9 of the 10 largest values are accurately captured in the Compustat data. ${ }^{7}$ For the remaining observation, we were able to verify investment but not property plant and equipment due to one missing financial statement. Our data check suggests that the extreme values are correctly captured by Compustat and, as a result, there is no justification for Winsorizing the data on the assumption that extreme values are data errors.

\subsection{National, Rather Than Local, Shocks to Real Estate Prices Matter for Investment}

CST's identification strategy is based on the comparison of investment by land-holding firms across areas with different variations in real estate prices (page 2382). We reexamine the robustness of this identification to the presence of aggregate real estate shocks that are common to all real estate holding firms.

An Econometric Correction to Eliminate Bias:

Before proceeding, we make an econometric correction to CST's baseline specification (2.1). The reason for this correction is as follows: The variable of interest, $R E$ Value $_{i t}$, is an interaction term between (i) the initial book value of real estate

\footnotetext{
${ }^{6}$ Financial statements can be found at the SEC's Electronic Data Gathering, Analysis and Retrieval System (EDGAR) website https://www.sec.gov/edgar.shtml.

${ }^{7}$ The table is available upon request.
} 
$R E \widetilde{\text { Value }}_{i, 1993}$ normalized by $P P E_{i, t-1}$ and (ii) $P_{t}^{l}$, given as

$$
R \text { Value }_{i t}=P_{t}^{l} \times \frac{R E \widetilde{\text { Value }}_{i, 1993}}{P P E_{i, t-1}} \equiv P_{t}^{l} \times R E \text { Value }_{i, 1993}
$$

where $R E$ Value $_{i, 1993}$ is the the initial market value of real estate in 1993 normalized by lagged Property Plant and Equipment, $P P E_{i, t-1}$.

Balli and Sørensen (2013) show that if a regression has an interaction term, say $X_{1} * X_{2}$, then the main terms $X_{1}$ and $X_{2}$ should be included in the empirical specification. If the main terms are not included then the interaction effect may be significant due to left-out variable bias. Since CST include only one of the main terms $P_{t}^{l}$ but not $R E$ Value $_{i, 1993}$, it is likely that the estimated $\beta$ is subject to this source of bias. Following Balli and Sørensen (2013) recommendation, therefore, we include $R E$ Value $_{i, 1993}$ in the empirical specification. ${ }^{8}$

Aggregate Shocks to Real Estate Holding Firms:

We introduce the aggregate shocks that are common to all real estate holding firms by considering firms' real estate value at the national price level denoted as $P_{t}^{N} .9$

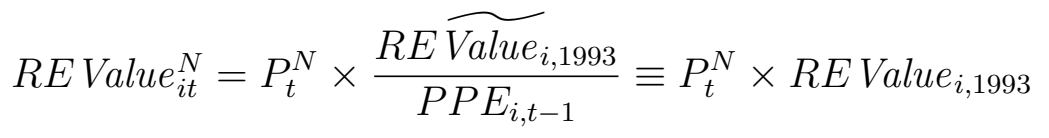

The modified specification that we estimate is

$$
I N V_{i t}^{l}=\alpha_{i}+\delta_{t}+\beta R E \text { Value }_{i t}+\phi R E \text { Value }_{i t}^{N}+\gamma P_{t}^{l}+\psi R E \text { Value }_{i, 1993}+\text { controls }_{i t}+\varepsilon_{i t}
$$

We do not include $P_{t}^{N}$ by itself in specification (2.5) as it is perfectly collinear with the year fixed effects $\delta_{t}$ which is already present in the regression.

\footnotetext{
${ }^{8}$ To ensure that the main term matches what is in the interaction term, we Winsorize $R E$ Value $_{i, 1993}$ and then multiply by $P_{t}^{l}$.

${ }^{9}$ Our national real estate price index is constructed by the Office of Federal Housing Enterprise Oversight. This is the same data source used by CST to measure MSA level real estate prices, $P_{t}^{l}$.
} 
Table 2.4: Real Estate Prices and Investment Behaviour: Local versus Aggregate Real Estate Shocks

\begin{tabular}{lcc}
\hline & Winsorized Data & Unaltered Data \\
\hline RE Value (MSA Res. Prices), $\beta$ & $\mathbf{- 0 . 0 1 6 4}$ & $\mathbf{- 0 . 0 1 5 4}$ \\
RE Value (National Prices), $\phi$ & $0.0452^{*}$ & -0.0576 \\
MSA Res. Prices, $\gamma$ & 0.001 & 54.221 \\
RE Value (1993), $\psi$ & 0.007 & 0.0522 \\
Cash & $0.030^{* * *}$ & -0.115 \\
Market/Book & $0.062^{* * *}$ & -0.022 \\
Init. Controls x MS Res. Prices & Yes & Yes \\
Year Fixed Effects & Yes & Yes \\
Firm Fixed Effects & Yes & Yes \\
Observations & 16,320 & 16,320 \\
Adjusted $R^{2}$ & 0.318 & 0.060 \\
\hline
\end{tabular}

Notes: Instrumental variables (IV) estimation (Saiz elasticity $\times$ interest rate). *** denotes statistical significance at the $1 \%$ level, ${ }^{*}$ denotes statistical significance at the $10 \%$ level.

The results in Table 2.4 show that even when the data is Winsorized as in CST, the main quantitative finding - the 6 cents sensitivity of investment to a $\$ 1$ increase in the real value of collateral a firm actually owns - is not robust to the econometric correction of their baseline specification and to the presence of aggregate real estate shocks common to all real estate holding firms. The sensitivity of investment to local real estate shocks, as in CST, is -1.6 cents and statistically insignificant while the sensitivity to aggregate real estate shocks is 4.5 cents, and statistically significant at the $10 \%$ level. ${ }^{10}$ This finding shows that CST's identification strategy based on local variations in real estate prices does not identify a firm's investment sensitivity to each additional dollar of real estate that the firm actually owns. ${ }^{11}$ Again, in the unaltered data there is no evidence for the collateral channel as shown in the third column of

\footnotetext{
${ }^{10}$ For the Winsorized data, when only the econometric correction is considered in the empirical specification, the estimated sensitivity reduces by half from approximately 6 cents as in Table 2.1 to approximately 3 cents. In the unaltered data, there is no evidence for the sensitivity of investment to real estate shocks. These results are available upon request.

${ }^{11}$ We also checked whether land holding firms make larger debt issuances and repayments when the value of their real estate increases (Table 8 in CST). The results for local shocks to real estate value are statistically insignificant, similar to those in Table (2.4) for the Winsorized data.
} 
Table 2.4.

\subsection{Conclusion}

We re-examine the finding of CST that over the 1993-2007 period, a $\$ 1$ increase in collateral (the value of real estate a firm actually owns) leads the representative US public corporation to raise its investment by $\$ 0.06$. We first replicate their paper and confirm their finding. We then demonstrate that in a wide sense their findings are highly sensitive to the Winsorization threshold. Since the largest investing firms do not hold real estate, Winsorization mechanically reduces their influence and biases the analysis in favour of finding evidence for the collateral channel. We also showed that even with Winsorized data, corporate investment is affected by aggregate real estate shocks instead of local real estate shocks. This finding, therefore, shows that CST's identification based on local real estate price variation does not provide evidence on the collateral channel.

Overall, our findings have three implications for future research. First, the empirical relevance of the collateral channel remains on open question. Second, strategic competition and market structure considerations might be more important drivers of US corporate investment than ownership of real estate collateral. Third, more

generally, researchers should discuss how Winsorization alters the original data and whether or not it pushes the data closer to the maintained theory of interest. 


\section{Chapter 3}

\section{The Impact of Macroprudential}

\section{Housing Finance Tools in Canada}

\subsection{Introduction}

Since the global financial crisis, macroprudential housing-finance tools have been increasingly utilized to reduce financial system vulnerabilities related to housing market imbalances (Galati and Moessner (2013) and Claessens (2015)). ${ }^{1}$ Despite broad-based implementation, the effectiveness of such policies are not well understood. This paper attempts to fill this gap by analyzing loan-level data on first-time homebuyer (FTHB) mortgage choices in Canada over a period of changing macroprudential regulation. To quantify the aggregate impacts of macroprudential policy on borrower behavior and the dynamic responses of total credit, we propose, calibrate, and implement a microsimulation model of mortgage demand.

Macroprudential policy can directly affect household borrowing through wealth and income constraints by limiting or expanding access to the mortgage market.

\footnotetext{
${ }^{1}$ This chapter of my thesis has been accepted for publication in the Journal of Financial Intermediation. See Allen et al. (2017) for the accepted manuscript which is available at https://doi.org/10.1016/j.jfi.2017.08.004.C $<2017>$. This manuscript version is made available under the CC-BY-NC-ND 4.0 license.https://creativecommons.org/licenses/by-nc-nd/4.0/
} 
The macroprudential tools we analyze include changes to the maximum allowable amortization and the maximum allowable LTV ratio. Changes to amortization affect how much of a household's income is directed to its monthly mortgage payment. Between 2006 and 2007, we observe that the maximum allowable amortization period increased from 25 to 40 years. This is followed by a similar sized tightening in 2008 . The second macroprudential change was to the maximum allowable LTV ratio, which is closely related to wealth. A relaxation of the LTV requirement allows individuals to enter the housing market with less financial wealth, while a tightening has the reverse effect. In 2006, regulatory changes were made to allow for $100 \%$ LTV loans, up from $95 \%$. The LTV was tightened back to $95 \%$ in $2008 .^{2}$

The first contribution of this paper is to present descriptive evidence of the impact of changes in Canadian macroprudential housing-finance policy on household demand for mortgage credit using detailed data on FTHB mortgage contracts. Our data cover the period 2005 to 2010, during which macroprudential tools were both loosened and tightened and when the housing market experienced a prolonged boom followed by a short bust and a long rebound. Institutional features of the Canadian mortgage environment - the fact that by law, mortgage insurance is required on all high LTV mortgages, and that this insurance is backed by the federal government-allows us to focus on the effectiveness of macroprudential tools without modeling the endogenous supply of credit, which hampers most empirical work in this literature. Given that mortgages are fully insured by the government, lending is free of default risk allowing us to assume credit is supplied elastically and that any impact from macroprudential policies is driven by demand and the effect of the policies on households' borrowing constraints.

There are two main results from our analysis of the loan-level data, which is easiest to interpret if we assume that households target a fixed mortgage payment.

\footnotetext{
${ }^{2}$ According to the IMF (2013), LTV constraints appear to be the most popular macroprudential tool used by authorities to manage demand for household credit.
} 
That is, households budget a fixed percentage of their income towards housing in the same way that households budget for consumption, savings, etc. ${ }^{3}$ First, we find that on average, households are more constrained by savings (wealth) than monthly cash flow (income). A key observation is that households' average monthly mortgage payments increase even as the government slackens the income constraint. Only a small fraction of households take advantage of the longer allowable amortization to lower their monthly payments. Most choose larger mortgage payments. This suggests that the majority of FTHBs were not constrained by income.

We do observe, on the other hand, a substantial increase in the fraction of households with no more than $5 \%$ equity at origination as the LTV constraint is loosened. Given that most households have sufficiently high income to make their mortgage payments, their demand for credit increased as the LTV constraint was loosened. Once the LTV constraint is loosened, most households are able to increase leverage and make the larger monthly mortgage payments they desired. The results we obtain during the tightening period are similar: as the government lowers the maximum allowable amortization length and LTV there is a greater fraction of borrowers at the maximum allowable LTV. FTHBs make larger down payments as a fraction of their income as house prices continue to rise, but more households are at the LTV constraint. We also observe a decrease in average monthly payments, driven by accommodating monetary policy. However, the total debt-service ratio remains flat, indicating that non-mortgage debt is higher. If households could borrow more they would, further highlighting the role of the LTV constraint.

Although our descriptive analysis of the observed choices of consumers provides valuable insight, it is difficult to quantitatively measure the impact of a change in an income constraint or wealth constraint on consumer choice. It is also difficult to con-

\footnotetext{
${ }^{3}$ Although not strictly necessary, it is helpful to think of households choosing to budget in fixed proportions. Gorman (1964) shows when this is optimal (utility is additively separable) and Davis and Heathcote (2005) provide evidence that this was at least true in the U.S. over the period that they study (1984-2001), justifying Cobb-Douglas utility over housing, consumption, and leisure.
} 
duct scenario-analysis - experiments we might be interested in include the impact of monetary policy shock or a house price correction. Individuals are sorting themselves along several dimensions, for example, housing choice, in addition to the different mortgage contract options. Furthermore, the macroeconomic environment, including monetary policy, is changing throughout our sample. Our second contribution, therefore, is to use a microsimulation model of mortgage demand to summarize the quantitative impacts of the changes in macroprudential policies on FTHB mortgage demand. We label this model HRAM, which stands for Household Risk Assessment Model. This model imposes some structure on how we interpret the data while still being highly flexible in capturing nonlinear responses that more traditional, rational forward-looking dynamic general equilibrium models generally have difficulty capturing.

The model imposes the following structure: there is a set of heterogeneous renters and homeowners. Every period a renter can qualify to become a homeowner if they have enough income and wealth to afford a house. This depends on the renter's characteristics as well an exogenous process for their income, financial assets, regional house prices, and the macroeconomic environment. The model, therefore, is not one with optimizing households. The probability that a renter in the survey data qualifies for and purchases a house, however, is chosen to match the loan-level data based on the joint distribution of income and monthly mortgage-payment-to-income (PTI) and LTV ratios. ${ }^{4}$ When the government changes access to mortgage insurance it affects the probability of renters qualifying to become homeowners and whether or not they purchase a house. Using the model, therefore, we can map the impact of a policy change on the percentage of FTHBs who have sufficient wealth to enter the market, whether they purchase a house, and their demand for credit.

\footnotetext{
${ }^{4}$ Greenwald (2015) shows that matching both the PTI and LTV ratios are crucial for understanding mortgage demand. Corbae and Quintin (2015) make similar arguments for understanding foreclosures.
} 
The results of our microsimulation model suggest that the wealth constraint has the largest impact on the number of FTHBs who enter the housing market. However, for FTHBs who have accumulated wealth, changes to the income constraint can also be substantial. This is because, conditional on income, high-wealth individuals are much more likely to own homes than low-income individuals. For example, we find that the tightening of the LTV constraint from $100 \%$ to $95 \%$ led to a $51 \%$ decrease in loan qualifications, a $7.9 \%$ decrease in FTHBs, and an $8.1 \%$ decrease in mortgage debt. We observe a $4.8 \%$ decrease in loan qualifications, a 3.6\% decrease in FTHBs, and a $7.2 \%$ decrease in mortgage debt following a tightening in the amortization from 35 to 30 years. The impact of tightening the LTV is more than 10 times larger on qualifying to purchase a starter home, and the change in the number of FTHBs is larger following a change in LTV; however, the average mortgage size falls by about the same amount following changes in LTV and amortization. We also conduct several interest rate experiments that allow us to test the vulnerability of households to rate changes. We examine the impact of an unexpected 200 basis point increase in interest rates under different macroprudential scenarios. The goal is to measure the relative importance of LTV versus PTI policies at mitigating household risk. We find that household arrears are lower in an environment with tight LTV put loose PTI policies compared to an environment with loose LTV but tight PTI policies. This further suggests that LTV policies are the most relevant for Canadian households.

This paper is related to the nascent but growing literature on the impacts of macroprudential tools on households, financial institutions, firms, and the aggregate economy. Using Korean data, Igan and Kang (2011) find house prices and transactions respond to changes in LTV, although not leverage. Han et al. (2016) study the Canadian market and the $\$ 1$ million cap on mortgage insurance implemented in 2012. They conclude that for macroprudential policy to be effective it must be targeted at liquidity-constrained borrowers, and that policy-makers need to take into 
account how agents (lenders, buyers, sellers) will respond to the regulation. de Araujo et al. (2016) use Brazilian credit registry data and find that tightening of the LTV leads to a change in the composition of borrowers. Work at the International Monetary Fund (IMF) and Bank for International Settlements (BIS) has focused more on the impact of macroprudential tools on bank lending. ${ }^{5}$ See for example Cerutti et al. (2017) and Kuttner and Shim (2016).Also Baster and Koch (2014) find that capital-constrained mortgage lenders increased rates in response to tighter capital requirements in Switzerland. ${ }^{6}$

Our paper is also related to the small set of papers that have used microsimulation models to study vulnerabilities in the household sector. This includes papers on Finland (Herrala and Kauko (2007)), Sweden (Johansson and Persson (2006)), Chile (Fuenzalida and Ruiz-Tagle (2011)), and Italy Michelangeli and Pietrunti (2014). Microsimulation models provide an advantage in that they can summarize large amounts of micro-level information and inference can be made about what changes might be expected regarding hypothetical policy changes (Harding (1996) and Gupta and Kapur (2000)). Compared with these papers, we focus on modeling mortgage demand with the explicit goal of understanding how consumers respond to changes in macroprudential policy.

The paper is organized as follows. Section 3.2 presents institutional details of the Canadian mortgage market. Section 3.3 highlights the key macroprudential rule changes implemented in Canada between 2005 and 2010. Section 3.4 presents the data. Section 3.5 presents the microsimulation model and and policy experiments, and Section 3.6 concludes.

\footnotetext{
${ }^{5} \mathrm{As}$ part of the CCA CGDFS working on the impact of macroprudential policies, Gómez et al. (2017), Levin et al. (2017) and Cabello et al. (2017) all measure the impact of dynamic provisioning schemes, either in Columbia, Mexico, or Peru, respectively. All find that dynamic provisioning had a negative impact on credit growth.

${ }^{6}$ The impacts of macroprudential tools have also been studied in dynamic stochastic general equilibrium (DSGE) models. Lambertini et al. (2013) and Angelini et al. (2012) are just two examples.
} 


\subsection{Institutional Background}

Canada's Bank Act (section 418) requires mortgage insurance on all high-ratio mortgages, where high-ratio is defined as less than $20 \%$ equity at origination. With insurance, financial institutions are willing to lend to borrowers previously excluded from the mortgage market. Since high-ratio mortgages are insured, financial institutions do not face default risk. ${ }^{7}$ Furthermore, there are steep prepayment penalties in Canada, limiting lender prepayment risk.

Conditioning mortgage access on mortgage insurance also allows the government to change access through insurance guidelines $/$ rules. $^{8}$ In response to the 1991 recession mortgage insurance underwriting guidelines were loosened to spur housing investment. This continued throughout the mid-1990s and early and mid-2000s. However, following the onset of the global financial crisis and growing imbalances in Canada's housing markets, the government tightened mortgage insurance access between 2008 and 2016 by lowering the maximum allowable amortization length and LTV and debtservice ratios, and reintroduced house price caps for mortgage insurance. We discuss some of these changes in Section 3.3. See Schembri (2014) and Crawford (2015) for a discussion of Canada's policy framework and how it functioned during the crisis.

Mortgages in Canada are typically 5-year fixed-rate contracts (term) with a 25year amortization, and insurance is the life of the mortgage. The insurance premium is a one-time fee that depends on the LTV ratio. Access is conditional on being below a maximum debt-service ratio and, more recently, above a minimum credit score. ${ }^{9}$ Borrowers have the option to roll-in the premium into the loan, which is almost always

\footnotetext{
${ }^{7}$ About half of total mortgage credit is uninsured, i.e. more than $20 \%$ equity at origination. Banks do face default risk on these mortgages. In addition to being high-equity, most provinces, however, have full recourse mortgages, meaning that most Canadians who forfeit on their homes would owe the difference between the recovered value of the house and the face value of the mortgage.

${ }^{8}$ The government also has authority over mortgage securitization since CMHC is in charge of securitizing insured mortgages. We abstract from changes to securitization, which is almost entirely public (Mordel and Stephens (2015)), that could affect bank funding.

9 The government introduced LTV-based pricing in 1982. Premiums are determined by CMHC and are set to meet certain capital requirements. The private insurers follow CMHC's pricing.
} 
done. The qualifying rules and premiums are common across insurers and lenders.

Finally, there is one public insurer, Canada Mortgage and Housing Corporation (CMHC), and two private insurers (Genworth Financial and Canada Guaranty). In

the case of borrower default, lenders are protected by the insurer. In the case of borrower and insurer default, lenders have a government guarantee that pays $100 \%$ if the mortgage is insured by $\mathrm{CMHC}$ and $90 \%$ if it was insured by a private insurer. The government therefore establishes mortgage insurance regulations and guidelines to manage its contingent liabilities stemming from vulnerabilities related to housing markets and household indebtedness.

\subsection{Mortgage Access Constraints and Rule Changes}

In this section we highlight some key changes to mortgage insurance guidelines over the period 2005 to 2010 . We analyze the impact of most of these changes on household mortgage demand in what follows. The main rule changes were to the LTV constraint and the amortization length, the latter of which operates through the TDS constraint.

\subsubsection{Mortgage insurance constraints}

Access to mortgage credit is controlled through mortgage insurance guidelines, especially those related to LTV and TDS constraints. The LTV constraint is simply that the ratio of loan size to house value has to be less than $\overline{L T V}$, where historically in Canada $\overline{L T V}$ has fluctuated between 90 and 100 and is currently at 95. The TDS constraint is defined as follows:

$$
\left(\frac{\text { mortgage payment }+ \text { other housing costs }+ \text { other debt payments }}{\text { household income }}\right) \times 100 \leq \overline{T D S}
$$

where $\overline{T D S}$ in Canada is currently 44. A borrower's PTI is their mortgage payment as a fraction of household income. 
The impact of changes to the income and wealth constraints can be best understood by considering a borrower's housing and mortgage choice problem. An increase in $\overline{L T V}$, allows the household to borrow more for the same housing choice. If $\overline{L T V}$, equals 100, the household can borrow the full value of the house, subject to the TDS constraint. For the TDS constraint, given a fixed level of non-mortgage debt, an increase in the maximum allowable amortization loosens the payment constraint. Households that are income-constrained therefore benefit from longer amortization periods.

\subsubsection{Rule changes}

The specific rule changes we study are as follows. First, on February 25, 2006 CMHC increased its maximum amortization from 25 to 30 years in what was supposed to be a four-month pilot program. ${ }^{10}$ Soon after, on March 16, 2006, Genworth Financial (Genworth) increased its maximum amortization from 25 to 35 years. On June 28, 2006, CMHC allowed contracts to amortize over 35 years and matched Genworth's insurance premiums. Following these increases in amortization, on October 2, 2006 Genworth increased the maximum allowable LTV from 95 to 100. This was followed closely on October 10, 2006 when Genworth increased its maximum amortization from 35 years to 40 years. On November 19, 2006 CMHC increased its maximum allowable LTV from 95 to 100, and also increased its maximum amortization from 35 to 40 years. We label the period February 25, 2006 to November 14, 2008 as the "loose" period in the data.

The "tightening period" begins October 15, 2008. The tightening concerned changing amortization lengths for high-ratio mortgages from 40 to 35 years and LTV ratios from 100 to 95, and imposing a new TDS constraint of 45. The government

\footnotetext{
${ }^{10}$ The insurance premium for this product was an additional 25 basis points. We do not believe that small changes in insurance premiums affect demand. Premiums are amortized over the full amortization period, and therefore represent only a small fraction of the cost of borrowing. In our analysis of premium changes we do not find any impact on borrower demand.
} 
also established a minimum credit score and loan documentation standards.

\subsection{Data}

In this section we introduce the main variables used in our analysis for the individuallevel data at mortgage origination. These data form the basis of our descriptive analysis of the impact of the changes in macroprudential regulation on mortgage contracts. We also use these data to discipline the household-level survey data and therefore calibrate the microsimulation model presented in Section 3.5.

\subsubsection{Mortgage insurance data}

Information on the mortgage contract, borrower, and lender is collected by CMHC at the time of origination for all insured mortgages. The information collected includes the interest rate, loan amount, house price, debt-service ratio, term, amortization, household income, credit score, and lender name. On average, $60 \%$ of contracts are new originations and $40 \%$ are refinancing. We drop all refinancing and focus on the more homogenous set of new originations. Since our focus is on FTHBs, we also drop all repeat buyers. Approximately $20 \%$ of new originations are repeat buyers. ${ }^{11}$ Table 3.1 presents summary statistics of the key variables for three subperiods using the population of CMHC-insured FTHB residential purchases. Dollar values are in nominal CAD except where noted. The subperiods broadly coincide with a "pre" period, a "loosening" period, and a "tightening" period. The pre-period is from February 24, 2005 to February 24, 2006, and occurs before the rapid loosening of insurance guidelines for fixed-rate mortgages. The loosening period corresponds to

\footnotetext{
${ }^{11}$ Anenberg and Bayer (2013) point out that the internal movement of repeat buyers is especially volatile $-20 \%$ of U.S. originations in down years and $40 \%$ in peak years. Allen et al. (2014) document that repeat buyers take out larger loans to purchase larger homes than FTHBs. However, on average, they have lower LTV ratios and similar TDS ratios as FTHBs. Where repeat buying is likely more volatile is in the uninsured mortgage space, where we do not have data, and outside the scope of macroprudential policy.
} 
February 25, 2006 to October 14, 2008, during which mortgage insurance guidelines for amortization length and LTV were relaxed multiple times. We focus our discussion on the cumulative impact of the loosening on mortgage contract characteristics such as amortization, LTV, TDS, and interest rates. We also examine the impact of rule changes on average borrower income. Finally, the tightening period corresponds to October 15, 2008 to April 18, 2010. ${ }^{12}$ Over this period, the government tightened amortization, LTV, and TDS constraints. These periods form the basis for measuring the impact of macroprudential changes on mortgage demand. ${ }^{13}$

From Table 3.1, we observe a noticeable increase in loan size over time, which is not surprising given the increases in house prices. Incomes have also increased over time. LTV ratios appear relatively flat in Table 3.1; however, the amortization length and TDS ratios are increasing. The average age of an FTHB is 35. From Table 3.1 we see that the fraction of contracts that are fixed-rate mortgages is high, nearly $90 \%$. The percentage of variable-rate mortgages, however, increases at the end of 2008 as the central bank cut interest rates and offered forward guidance that set expectations that rates would be low for some time (Mendes and Murchinson (2014)). Finally, we also present an indicator for whether the source of the down payment was unconventional; this includes sweat equity, second lien, gifts, or nontraditional sources. On average, these represent 25\% of cases. Most down payments

\footnotetext{
${ }^{12}$ On April 19, 2010 the government changed the TDS formula for variable-rate mortgages (VRMs) and for mortgages of terms longer than five years, which substantially affects loan qualifying. Our data ends in December 2010 therefore we do not study this particular rule change and cut the sample just prior to its enactment. We therefore also miss some of the further tightening that occurred between 2011 and 2016. See Crawford (2015) for a complete discussion of rules changes in Canada over the last two decades.

${ }^{13}$ There is one technical complication when forming the sub-periods. On average the time between application and closing is 45 days. For tightening episodes, both the application and closing dates are important since lenders typically provide a 90-day rate guarantee. The mortgage tightening therefore applies immediately on the announcement day to borrowers without pre-approval and applies approximately 90 days later (implementation date) for those pre-approved under the old rules. Therefore, individuals with a closing date after the implementation date are considered affected by the change, and individuals with closing dates before the announcement are considered unaffected. Individuals who closed during the phase-in time are not considered affected if they applied before the announcement. For loosening, the announcement and implementation dates coincide.
} 
Table 3.1: Summary statistics of transaction-level data for new purchases We present house prices both in nominal terms and deflated using the consumer price index. All dollar figures are in CDN dollars. Mortgage is the loan size. The variable (rate-bond) represents an estimate of a lender's profit margin. It's the contract rate minus funding costs, approximated by the matched-term Government of Canada bond rate. Income captures total household income. $\mathrm{I}(\mathrm{FRM})$ is an indicator variable equal to 1 if the mortgage is fixed-rate and 0 if variablerate. $\mathrm{I}(\mathrm{FICO} \geq 680$ ) is an indicator equal to 1 if the borrower's (best) credit score is at least 680 . $\mathrm{I}(\mathrm{DP}=$ unconventional $)$ is an indicator equal to 1 if a borrower's down payment was non-traditional such as a gift and 0 otherwise.

\begin{tabular}{|c|c|c|c|c|c|c|}
\hline & \multicolumn{2}{|c|}{$\begin{array}{l}2005 / 02 / 24- \\
2006 / 02 / 24\end{array}$} & \multicolumn{2}{|c|}{$\begin{array}{c}2006 / 02 / 25- \\
2008 / 10 / 14\end{array}$} & \multicolumn{2}{|c|}{$\begin{array}{c}2005 / 02 / 24- \\
2010 / 04 / 08\end{array}$} \\
\hline & mean & std & mean & std & mean & std \\
\hline House price (nominal) & 207,614 & 103,627 & 247,680 & 128,231 & 292,234 & 141,962 \\
\hline House price (real) & 192,528 & 95,936 & 221,016 & 114,829 & 254,813 & 123,717 \\
\hline Mortgage & 190,646 & 93,024 & 228,783 & 117,140 & 267,405 & 129,158 \\
\hline Income & 78,523 & 38,817 & 87,389 & 46,108 & 91,105 & 49,244 \\
\hline rate-bond & 1.05 & 0.63 & 1.29 & 0.74 & 1.99 & 0.85 \\
\hline $\mathrm{I}(\mathrm{FRM})$ & 0.93 & 0.26 & 0.91 & 0.28 & 0.87 & 0.34 \\
\hline Term(months) & 58.82 & 15.05 & 59.99 & 12.85 & 56.33 & 12.69 \\
\hline $\mathrm{I}(\mathrm{FICO} \geq 680)$ & 0.77 & 0.42 & 0.78 & 0.41 & 0.84 & 0.37 \\
\hline $\mathrm{I}(\mathrm{DP}=$ unconventional $)$ & 0.27 & 0.44 & 0.25 & 0.43 & 0.24 & 0.43 \\
\hline
\end{tabular}

are from either private or registered savings plans.

In Figure 3.1 and Figure 3.2 we graphically present the main variables of interest over the full sample for FTHBs. All dates are based on closing and not application. The contract variables of interest are amortization, LTV, TDS and PTI. Broadly speaking, there are three periods: the shaded area denotes a period of loosening; the period immediately following is a period of tightening; and the first year represents a period with no change in mortgage insurance guidelines. From the figures we can clearly observe an increase in amortization, LTV, and TDS during the loosening and a similar decrease during the tightening. Figure 3.2(b) captures only the monthly mortgage payment component of TDS. Mortgage payments between 2006 and 2008 are increasing even as amortization lengths are increasing, which loosens the income constraint. This is because monetary policy is tightening, making mortgages more expensive, and also because the wealth constraint is loosening and households are 
borrowing more.

Figure 3.1: Amortization length and LTV for FTHBs

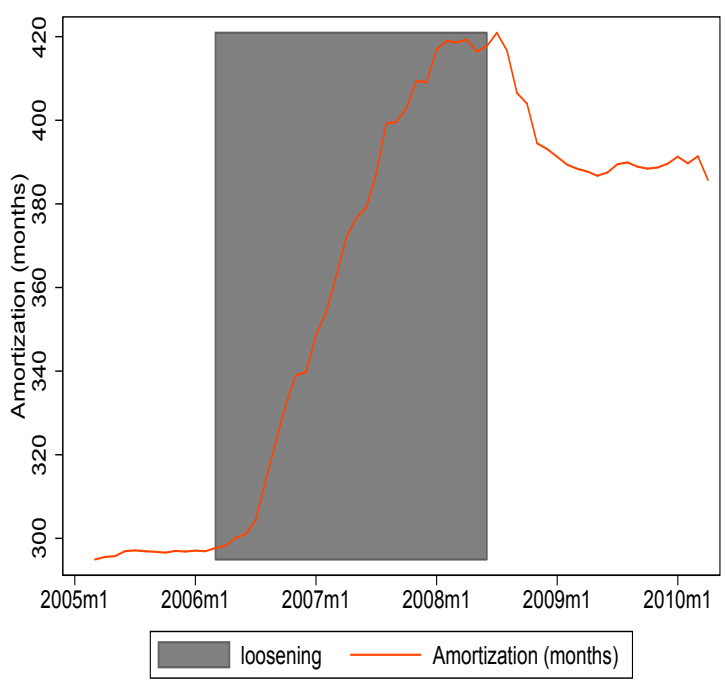

(a) Amortization

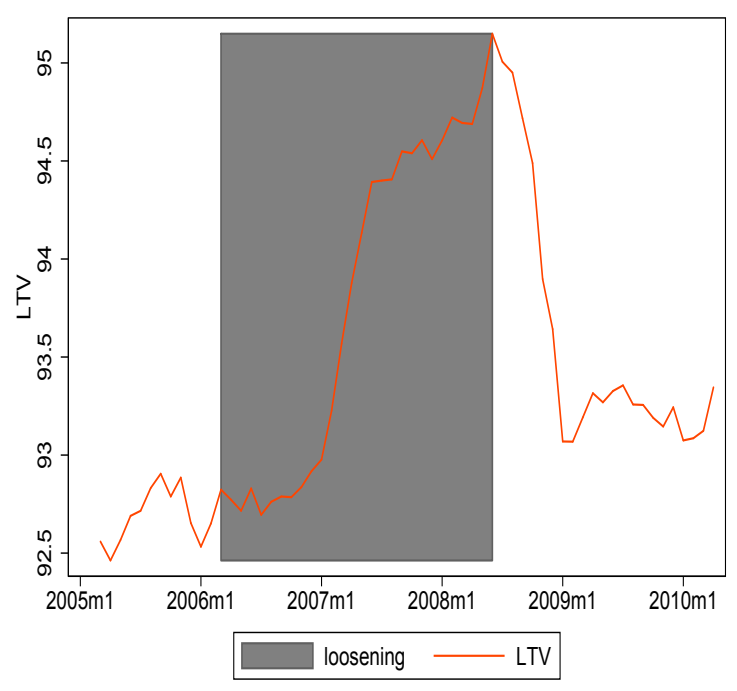

(b) LTV

Figure 3.2: Average TDS and monthly PTI ratio for FTHBs

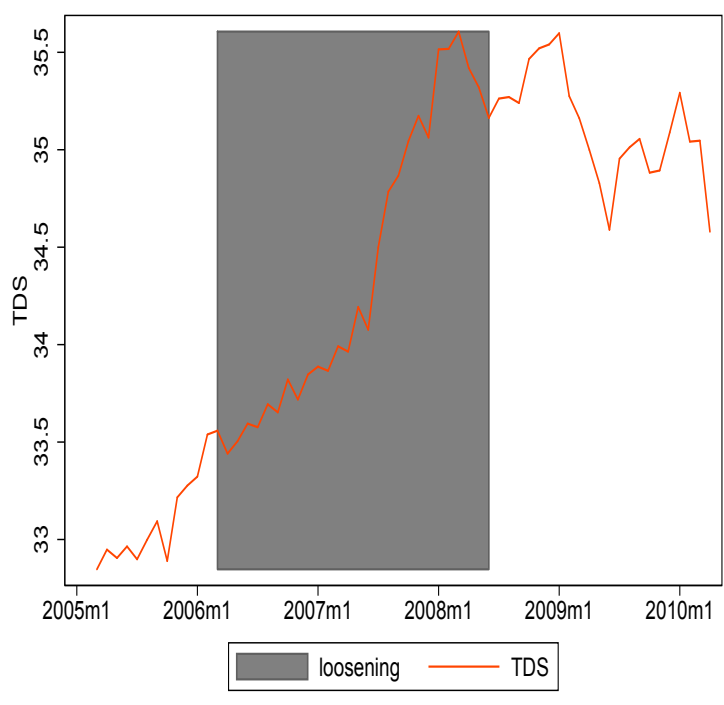

(a) TDS

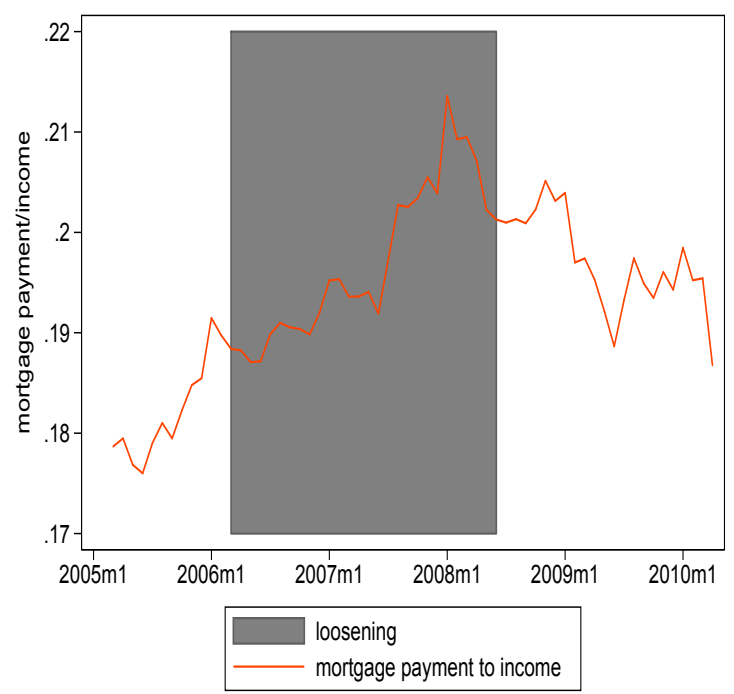

(b) PTI 


\subsubsection{Data-driven analysis}

Our empirical analysis focuses on the demand for credit and how both mortgage contract characteristics and borrower characteristics were affected by changes in mortgage insurance guidelines. We focus on FTHBs choosing five-year fixed-rate mortgages.

The main specification is equation (3.1) where $y$ is our variables of interest: LTV, amortization, TDS, down payment-to-income ratio, monthly PTI, house prices, loan size, household income, and interest rates. $D_{j}$ is an indicator variable equal to 1 for the period under which mortgage insurance rule $j$ is in place and 0 otherwise. We estimate equation (3.1) for two samples. First, where $D_{1}$ equals 1 during the loosening period from February 25, 2006 to July 8, 2008 and 0 from February 24, 2005 to February 24, 2006. Second, where $D_{2}$ equals 1 during the tightening period from July 9, 2008 to April 18, 2010 and 0 during the loosening period. We also include month fixed effects interacted with location fixed effects $\left(\nu_{m}\right)$, where location is an FSA. ${ }^{14}$ This allows us to control for location-specific seasonality (for example, housing demand might be different in Vancouver and Montreal across seasons due to weather) and unobservable differences in housing market conditions. Standard errors are clustered at the FSA level. For covariates we include borrower characteristics such as age and broker-use, as well as property characteristics such as dwelling type and age. We also include bank fixed effects $\left(\theta_{b}\right)$.

$$
y_{i t}=\alpha_{0}+\beta X_{i t}+\gamma_{j 1} D_{j t}+\theta_{b}+\nu_{m}+\epsilon_{i t} .
$$

We present results for the loosening period (2006-2007) and the tightening period (2008-2010) in Table 3.2 and Table 3.3, respectively. Given that multiple tools were used in quick succession it is difficult to assign causation to any one particular tool or to present marginal effects. We therefore present the cumulative impacts and dis-

\footnotetext{
${ }^{14} \mathrm{An}$ FSA is a forward sortation area and is the first three letters of a Canadian postal code.
} 
cuss the broad relationships between changes in macroprudential tools and household borrowing and explore specific mechanisms that are likely at play. We do allow the policy variable, $D$, to interact with log-income (demeaned) when looking at LTV and amortization. We do this to explore consumer heterogeneity in response to lending policies. ${ }^{15}$

Our results highlight that most contract, borrower, and market characteristics respond to changes in mortgage guidelines. In addition, there is heterogeneity in impacts depending on income. This is why in section 3.5 we model income heterogeneity. The cumulative impact of loosening the LTV is correlated with a 1.1\% increase in income. This is likely because the relaxation of the wealth constraint allows high-income-low-wealth individuals to enter the housing market with smaller down payments, since they easily meet the income constraint. In contrast, we observe the probability of low-income individuals at the maximum LTV falling. Even though zero-down-payment mortgages are allowed during this period, households must still meet the income constraint, which is not feasible. In addition, not everyone has a preference for the largest feasible mortgage (e.g., Brueckner (1994)). Only 17\% of households took advantage of the zero-down product.

In column (3) of Table 3.2 we see that the cumulative impact of loosening is correlated with a $22.7 \%$ increase in the average amortization length and no heterogeneity by income. From column (4) we observe that as the maximum allowable amortization was increased from 25 to 40 years, the percentage of borrowers at the maximum constraint fell. This is because nearly $97 \%$ of borrowers were at the constraint preloosening and not all borrowers choose the maximum allowable amortization following the relaxation of the constraint. Given that amortization plays an important role in the income constraint (and not the wealth constraint), this suggests that for at least some incoming FTHBs, the income constraint was not binding. Column (5) presents

\footnotetext{
${ }^{15}$ Ideally, if data were available, we would also interact $D$ with financial wealth.
} 
the cumulative impact of the loosening on the average TDS while Column (6) presents the relationship for PTI. Both are large and significant. Why? House prices were rising substantially over the sample period, by $19.2 \%$ during the loosening period, and from column (10) we also see that interest rates were rising. From column (9) we also see that incomes increased by $11.8 \%$ during the loosening period. The result that mortgage payments increased, therefore, despite longer amortization and larger incomes is driven in large part by higher interest rates on larger loans. This suggests that borrowers were not income-constrained, but instead constrained by wealth. If households were truly constrained by income, mortgage payments should have remained flat as they took on longer amortizing mortgages.

Now consider the period of tightening mortgage insurance guidelines and the results in Table 3.3. This period affected the types of borrowers who could become FTHBs. House prices are continuing to rise but now monetary policy is being accommodating due to the global financial crisis. Lower interest rates allow for larger loans for the same TDS constraint, even though the amortization constraint is being tightened by the government. We observe the average TDS is unchanged from the loosening period and the mortgage-to-income ratio falls. This is because the new inflow of FTHBs have more non-mortgage debt than the previous cohort. They are constrained by their non-mortgage debt. They are also constrained by their savings. We observe a continued increase in the fraction of FTHBs at the maximum allowable LTV constraint even as households' down-payment-to-income ratio increases. This is especially true for high-income households. For income, the picture is more complicated. There are more households at the maximum allowable amortization, suggesting FTHBs are constrained. The average monthly-payment-to-income ratio, however, falls. This is driven by two facts. First, interest rates are falling as monetary policy is loosening. However, because of existing non-mortgage debt(tightening TDS) and because of the LTV constraint, they cannot borrow their desired amount. 


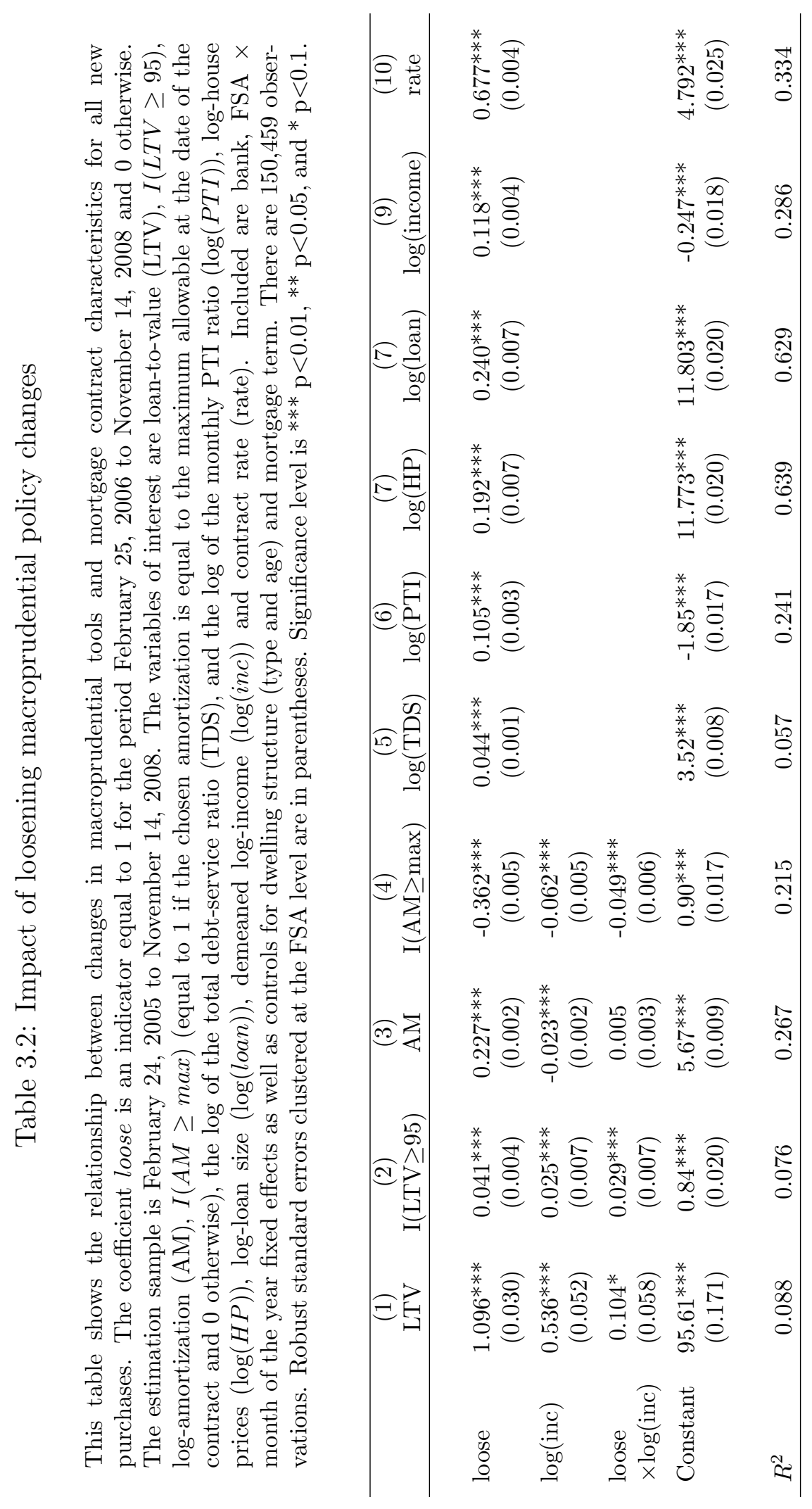




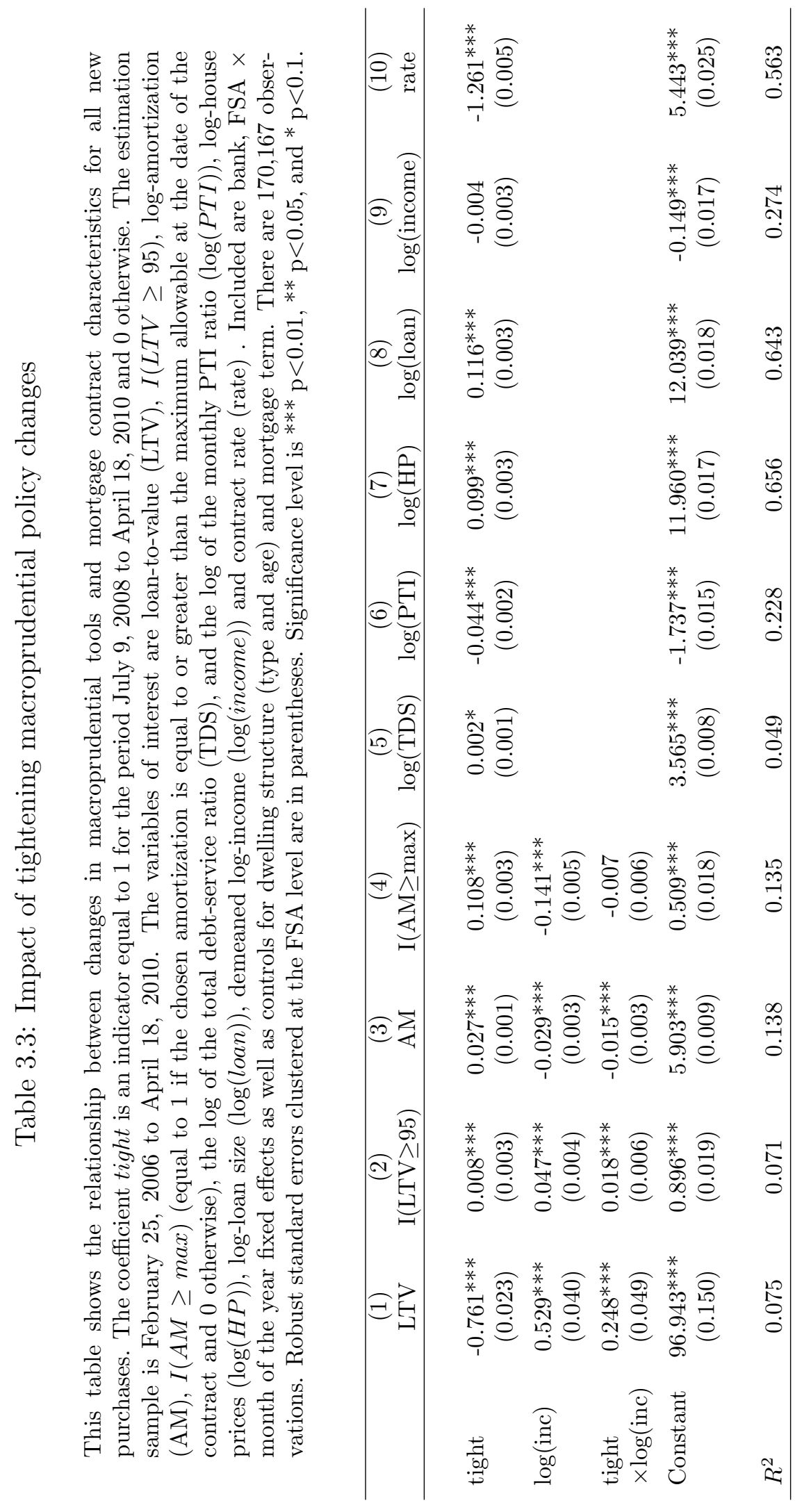




\subsection{Microsimulation Model}

Although our descriptive analysis provides some suggestive evidence on the effect of macroprudential policy on household borrowing, it is lacking in several dimensions. Most importantly, it does not offer a succinct answer to the question: What is the impact of macroprudential policies on mortgage demand? In this section, we present a general overview of our microsimulation model, HRAM.

Time is discrete, with a finite horizon given by $T$

$$
t \in \mathcal{T}=\{0,1,2, \ldots, T-1, T\}
$$

A household $i \in \mathcal{I}=\{1,2,3, \ldots, I-1, I\}$ is defined as

$$
i=\left(\Omega_{i},\left\{X_{i, t}\right\}_{t=0}^{t=T}\right)
$$

where $\Omega_{i}$ is a $J \times 1$ vector of fixed household characteristics, such as age, education, and geographic region, and $X_{i, t}$ is a $K \times 1$ vector of time-varying household variables, such as labor income and financial assets. Refer to an element in $X_{i, t}$ as $x_{i, t}^{k}$.

The nominal labor income of household $i$ in period $t$ is denoted by $x_{i, t}^{Y}$. Financial assets are denoted by $x_{i, t}^{F A}$, and housing assets by $x_{i, t}^{H A}$. The total financial resources available to household $i$ at time $t$, is the sum of labor income (minus tax payments) and financial assets (with the return) less debt:

$$
\underbrace{x_{i, t}^{F A}-x_{i, t}^{D}+x_{i, t}^{C}}_{\text {Asset, debt, consumption }}=\underbrace{x_{i, t}^{Y}(1-\tau)+x_{i, t-1}^{F A}\left(1+R_{t}^{F A}\right)-x_{i, t-1}^{D}}_{\text {Available financial resources }}-\underbrace{x_{i, t}^{D P}}_{\text {Required debt payments }}
$$

where $\tau$ is the tax rate on income, and $R_{t}^{F A}$ is the return on financial assets, which is assumed to be exogenous. 


\subsubsection{First-Time Homebuyers}

A three-stage approach is used to determine if a household, $i$, will be a FTHB in period $t$ :

1. Determine whether a household is a potential FTHB, $p_{i, t}=1$. Denote the complete set of potential FTHBs as $\mathcal{I}_{t}^{P}$.

2. Determine whether a potential FTHB qualifies for a mortgage, $q_{i, t}=1$. Denote the complete set of qualified FTHBs as $\mathcal{I}_{t}^{Q}$.

3. Determine a households down payment, and whether a qualified FTHB actually purchases a house, $b_{i, t}=1$. Denote the final set of buying FTHBs as $\mathcal{I}_{t}^{B}$.

We now present each step in the process.

\section{Potential FTHB}

For a household to be a potential FTHB, three conditions must be met: (i) a household must not currently own housing assets, $x_{i, t}^{H A}=0$, (ii) a household must be under 50 years old, and (iii) a household must be employed. ${ }^{16}$ If these conditions are met, $p_{i, t}=1$.

\section{Qualified FTHB}

We next turn to which households qualify for a mortgage. The home ownership process is driven by a mortgage debt-service shock, which is a function of household income. At time $\mathrm{t}=0$, all households that do not yet own a house draw a one-time idiosyncratic shock for their gross mortgage debt-service ratio (GDS), $\omega_{i}^{G D S}$, which is a function of household income:

$$
\omega_{i}^{G D S} \sim N\left(\mu\left(x_{i, 0}^{Y}\right), \sigma\right) .
$$

\footnotetext{
${ }^{16}$ The age restriction allows us to capture heterogeneity in preferences for renting.
} 
We calibrate the shock process for $\omega_{i}^{G D S}$ using the mortgage origination data, and allow for dispersion at the household level. This formulation assumes that a household has a deep underlying preference for the amount that it is willing to spend per month on its owner-occupied housing, akin to assuming that household $i$ would like to allocate a constant fraction of its gross income to meet mortgage payments.

Given a household's GDS preference shock, the mortgage chosen by household $i$ is given by

$$
x_{i, t}^{M O R T}=\omega_{i}^{G D S}\left[\frac{x_{i, t}^{Y}}{12}\right]\left[\frac{\left(1+r_{t}^{5} / 2\right)^{2 T}-1}{\left(\left(1+r_{t}^{5} / 2\right)^{1 / 6}-1\right)\left(1+r_{t}^{5} / 2\right)^{2 T}}\right],
$$

where $T$ is the amortization of the mortgage (measured in years) and $r_{t}^{5}$ is the nominal five-year fixed mortgage rate. Therefore, our assumption on debt servicing essentially determines the household's mortgage choice. For a given PTI shock, lower rates and longer amortization allow a household to take on a larger mortgage.

Modeling the down payment decision is more challenging. Given total household financial assets, the most valuable house that household $i$ can purchase is

$$
x_{i, t}^{H P M A X}=x_{i, t}^{M O R T}+x_{i, t}^{F A}
$$

with the associated maximum down payment:

$$
x_{i, t}^{D P M A X}=\frac{x_{i, t}^{F A}}{x_{i, t}^{M O R T}+x_{i, t}^{F A}} .
$$

Given these calculations, household $i$ faces three qualifying constraints:

1. (TDS: Income Constraint) Total household debt-servicing must be below the TDS threshold:

$$
\omega_{i}^{G D S}+\frac{x_{i, t}^{C D P A Y}}{x_{i, t}^{Y}} \leq \overline{T D S}
$$


where $x_{i, t}^{C D P A Y}$ is payments by households due to consumer debt (i.e., nonmortgage debt), and $\overline{T D S}$ is the regulatory cap on insured mortgage highlighted in Section 3.3.

2. (Down Payment Constraint) The down payment by household $i$ must be above the regulatory minimum:

$$
x_{i, t}^{D P M A X} \geq D P^{M I N}
$$

3. (Affordability) Through a combination of down payment and servicing a mortgage, a household must be able to afford an entry-level house:

$$
x_{i, t}^{H P M A X} \geq H P_{\text {Reg }_{i}, t}^{S T A R T E R}
$$

where $H P_{\text {Reg }_{i}, t}^{S T A R T E R}$ denotes the price of a starter home at time $t$ in the region in which household $i$ lives. The affordability constraint will also limit the choice of down payment for some households, since some households will need to make a large enough down payment in order to afford a starter house in their region.

If equations (3.6) to (3.8) are satisfied, then we say that household $i$ qualifies for a mortgage of size $x_{i, t}^{M O R T}$ and $q_{i, t}=1$. We denote the set of households that qualify for a mortgage as $\mathcal{I}_{t}^{Q}$.

\section{Buying FTHBs and Down Payment Decision}

Given the set of households that qualify for a mortgage, $\mathcal{I}_{t}^{Q}$, we next determine which households purchase a house in period $t$, as well as the down payment used to purchase the house. This is a complex problem, since there are many factors behind a homebuying decision, such as those related to family planning or employment opportunities. Furthermore, the down payment decision is complicated by the fact 
that some households may choose to not use all of their financial assets for the down payment. To simplify this decision, we partition the set of possible down payments into four categories:

$$
\mathcal{D P}=\{0 \%, 5 \%, 10 \%, 20 \%\}
$$

Using similar data, Allen et al. (2014) show that the nonlinearity of mortgage insurance pricing leads to bunching at these levels.

To simplify the homebuying decision, we make the homebuying and down payment decision a function of income and the minimum affordable down payment. Formally, we assume that for each period $t$, every household $i$ in $\mathcal{I}_{t}^{Q}$ receives a shock from the uniform distribution, $\varepsilon_{i, t}^{d p_{k}} \sim U[0,1]$, for each down payment $d p_{k}$ in $\mathcal{D} \mathcal{P}$ that is below $x_{i, t}^{D P M A X}$. For example, if $x_{i, t}^{D P M A X}=8 \%$, then household $i$ would receive two shocks: $\varepsilon_{i, t}^{0}$ and $\varepsilon_{i, t}^{5}$. A household then purchases a house with down payment $d p_{k}$ if

$$
\varepsilon_{i, t}^{d p_{k}} \geq Z_{t} \bar{\theta}\left(d p_{k}, x_{i, t}^{Y}\right)
$$

If equation (3.9) holds for more than one $d p_{k}$, then the household makes the larger down payment. The variable $Z_{t}$ is an aggregate shock that captures movements in housing demand that are not due to changes in mortgage qualification.

The calibration of $\bar{\theta}$ is the central part of the model where the structure speaks to the data. While the details are discussed in Section 3.5.2, the idea is that we discretize household income and perform a one-step generalized method of moments (GMM) calibration to match the joint distribution of income and down payments from the mortgage originations data shown in Table 3.6 and Table 3.7.

Due to the limited size of the household-level survey data, we limit the homebuying decision to only income and wealth (via the down payment). While this does not capture all of the potential factors influencing housing demand, such as age, eduction, etc., income and wealth are quite effective in capturing these factors. For instance, 
we have found in our calibration that higher-income and higher-wealth renters are more likely to become owners, which partially captures the effects of age.

Last, macro factors that might influence housing demand from unconstrained households can shift demand via the aggregate factor $Z_{t}$. The path of aggregate variables, such as house prices, interest rates and income is presented in Section 3.5.2 to be consistent with the actual path of these variables.

\subsubsection{Calibration}

The calibration uses loan-level transaction data from CMHC to identify those households most likely to become FTHBs in the household-level survey data. Table 3.4 summarizes the exercise. We start by identifying a set of potential FTHBs (Section 3.5.1). Second, there is a PTI preference shock that determines the amount of housing that would be assigned, which must be at least the minimum regional housing price to qualify (Section 3.5.1). Finally, there is the probability of purchasing a house (Section 3.5.1). The set of potential FTHBs is taken from a household survey, discussed below. This provides information on financial assets as well as detailed information about the characteristics of potential borrowers, including income, which is required to match the loan-level data. The PTI shock is used to find qualifying households among the set of renters identified in the first step, and to determine an amount of housing that would be assigned. These are chosen to match the joint distribution of income and PTI ratio of FTHBs in the loan-level data. The PTI draw must give an amount of housing that is greater than the minimum for that region. Finally, the probability that a qualifying individual purchases a house is determined by the joint distribution of that individual's income and down payment. We discuss each step in more detail. 
Table 3.4: Use of microdata in the calibration strategy

\begin{tabular}{lll}
\hline Data set & Uses & PTI shocks and Pr(purchasing) \\
\hline $\begin{array}{l}\text { Loan-level mortgage } \\
\text { insurance data (CMHC) }\end{array}$ & $\begin{array}{l}\text { Benchmark to help } \\
\text { describe FTHBs }\end{array}$ & $\begin{array}{l}\text { Determine moments for joint } \\
\text { distributions }\end{array}$ \\
\hline $\begin{array}{l}\text { Household survey data } \\
(\mathrm{CFM})\end{array}$ & Used in HRAM & $\begin{array}{l}\text { Match moments in the mortgage } \\
\text { insurance data }\end{array}$ \\
& $\begin{array}{l}\text { Doint distributions of GDS/income } \\
\text { assets \& income of FTHBs }\end{array}$ & and down payment/income \\
\hline
\end{tabular}

\section{Household survey data and the set of potential FTHBs}

In the first step, households are identified as potential FTHBs if they have sufficient wealth and income, and meet the criteria described in Section 3.5.1: that they do not currently own housing assets, are under 50 years old, and are employed.

The set of potential FTHBs is constructed using the household-level data summarized in Table 3.5 and taken from the Canadian Financial Monitor (CFM) survey, conducted quarterly by Ipsos-Reid, a survey and marketing firm, since 1999. The survey is of approximately 12,000 households per year and includes detailed information on assets and liabilities as well as socio-demographic information. Crucially, the survey includes homeowners and renters. The household-level data initialize the households in the model, so that the distribution of home ownership, income, and financial assets matches the distribution observed in the data. ${ }^{17}$ Home ownership is around $68 \%$. Whether a household that is currently renting can qualify for a mortgage will depend upon the household's income (whether the household can afford the monthly payment) and financial wealth (whether the household can afford the minimum down payment).

We provide summary statistics for two data sets, the first for 2005 and the second

\footnotetext{
${ }^{17}$ Specifically, we populate the households in the model with households from the survey data. We then replicate households according to their survey sample weights (replicated households will receive different idiosyncratic PTI shocks). Thus, we have a set of potential FTHBs who should be rich enough to match the heterogeneity in the data. Importantly, we are using the data on financial assets and household income from the survey to determine if a household can make a sufficiently large enough down payment and afford an entry-level home in order to qualify for a mortgage. In contrast, the loan-level data do not include household financial assets.
} 
an average over 2007-2008. In our policy experiments we use the first data set for the loosening scenarios, with FTHBs calibrated to the CMHC loan-level data from the pre-loosening period of 2005. We then measure the impact of loosening relative to a counterfactual benchmark case where macroprudential rules are not changed. Similarly, we use the second data set as the data for the tightening scenarios, with FTHBs calibrated to the CMHC loan-level data from the pre-tightening period of 2007-2008, to measure the impact of tightening. The impact of the tightening is also measured relative to a counterfactual benchmark case where macroprudential rules are not changed.

In the household-level survey data, the average potential FTHB had an average income of $\$ 65,779$ in 2005 and $\$ 67,614$ between 2007 and 2008. Financial assets are heterogeneous, and determine how binding the wealth constraint is for those buying a house. The average potential FTHB in 2005 had $\$ 55,193$ in 2005 , which is more than the 75th percentile, due to positive skewness. Between 2007 and 2008, potential FTHBs had, on average, financial assets of $\$ 29,225$, and again, this is more than the 75 th percentile. ${ }^{18}$

\section{Matching loan-level and household-level data}

The second step is to use the joint distribution of mortgage payments and income in the loan-level data to find matching potential homeowners in the household-level survey data. Table 3.6 and Table 3.7 show the breakdown of parameters that are determined from the CMHC loan-level data, to be used in the calibration for their respective exercises. As with the household-level data, there are two periods: the pre-loosening period of 2005 (Table 3.6), and the pre-tightening period of 2007-2008

\footnotetext{
${ }^{18}$ The average assets are substantially lower in the second period because during this period, the down payment required to purchase a house went from $5 \%$ to $0 \%$. While the financial crisis may have reduced household financial assets, this only became more pronounced in 2008Q4, and would not explain the drop in the 2007-2008 period relative to 2005. The fact that the mean of financial assets is more than the 75th percentile highlights the positive skewness in financial assets and that there are some affluent households who could easily afford a house but instead choose to rent.
} 
Table 3.5: Household variables used in HRAM from CFM household survey data This table provides summary statistics on the main variables in HRAM. The variables are for those households that qualify to purchase a house, not all potential households. $x_{i, t}^{Y}$ is gross household income; $\omega_{i}^{a g e}$ is the head-of-household age; $x_{i, t}^{F A}$ is total financial assets; and $x_{i, t}^{C D P A Y}$ is the consumer debt-to-income ratio. Outside of the survey data, we calibrate the mean interest rate to the five-year average discounted fixed-rate mortgage $\left(R^{5}\right)$ and provincial house prices to the average resale price based on Canadian Real Estate Association data $(H P)$. Finally, unemployment $(U R)$ is the average of total weeks unemployed divided by total weeks in the labor force observed over the sample period.

\begin{tabular}{l|llll|llll}
\hline Variables & \multicolumn{4}{|c}{2005} & \multicolumn{4}{c}{$2007-2008$} \\
& mean & $\mathrm{sd}$ & $\mathrm{p} 25$ & $\mathrm{p} 75$ & mean & $\mathrm{sd}$ & $\mathrm{p} 25$ & $\mathrm{p} 75$ \\
\hline$\left.x_{i, t}^{Y} \$\right)$ & 65,779 & 31,555 & 40,000 & 82,500 & 67,614 & 29,545 & 47,500 & 85,000 \\
$\omega_{i}^{a g e}$ & 37.2 & 7.9 & 28 & 42 & 35 & 7.9 & 28 & 42 \\
$x_{i, t}^{F A}(\$)$ & 55,193 & 95,746 & 14,150 & 48,250 & 29,224 & 58,254 & 1,500 & 27,550 \\
$x_{i, t}^{C D P}(\%)$ & 0.97 & 8.91 & 0 & 6.34 & 4.32 & 6.5 & 0 & 8.54 \\
$H P(\$)$ & 172,633 & 79,865 & 113,634 & 214,317 & 203,421 & 85,062 & 141,532 & 247,175 \\
$R^{5}(\%)$ & 4.93 & 0.45 & 4.63 & 5.31 & 5.50 & 0.30 & 5.39 & 5.63 \\
$U R(\%)$ & 6.6 & 9.4 & 0 & 9.2 & 7.9 & 10.8 & 0 & 11.4 \\
\hline
\end{tabular}

(Table 3.7). We determine the relative frequency distribution of FTHBs for 11 income classes, as well as for each income class, average PTI ratios, and the distribution of these FTHBs across key down payment categories. ${ }^{19}$ Each of these income classes in the set of potential FTHBs in the survey data, therefore, receives an average PTI ratio corresponding to what is presented in the table. The average PTI ratio with respect to income is somewhat hump-shaped; however, borrowers in the highest income category have lower ratios than the low-income borrowers, on average. In addition to matching the within-income-category average PTI ratio, we also match the between-dispersion in PTI ratios for each of our two periods. That is, the $\sigma$ in equation (3.2). For 2005 we calibrate $\sigma$ to 5.3 and for 2007-2008, we calibrate $\sigma$ to 5.5 .

The third and final step is to use the joint distribution of income and down payment for FTHBs in the loan-level data to determine the probability of a potential match in the household-level survey data of buying a house. Table 3.6 and Table 3.7 provide this information as well. We calibrate the LTV choices to three options in the pre-period and to four options in the loosening period. The fourth option is a

\footnotetext{
${ }^{19}$ The empirical distribution of down payment ratios is highly clustered around key ratios that define the laddered increases in mortgage insurance premium rates.
} 
Table 3.6: Loan-level data calibration: 2005

Calibration variables for HRAM. Potential FTHBs are drawn from CFM based on whether their income, PTI ratio, and LTV ratio characteristics match those in the loan-level data. Income is gross nominal household income. The distribution of LTV by income is based on the loan-level data. The fraction of FTHBs with an LTV of less than 80, i.e., outside of the insurance space, is based on CFM. The cross-sectional dispersion in $\mathrm{mp} /$ inc ( $\sigma$ in equation (3.2)) is 5.3.

\begin{tabular}{lccccc}
\hline $\begin{array}{l}\text { Income category } \\
(\$)\end{array}$ & $\begin{array}{c}\text { Frequency } \\
(\%)\end{array}$ & $\begin{array}{c}\text { PTI } \\
\text { mean }\end{array}$ & $95 \%$ & $\begin{array}{c}\text { LTV } \\
90 \%\end{array}$ & $80 \%$ \\
\hline $0-24,999$ & 0.8 & 17.8 & 58 & 26 & 16 \\
$25,000-34,999$ & 4.5 & 17.9 & 53 & 29 & 19 \\
$35,000-44,999$ & 9.8 & 18.2 & 50 & 31 & 19 \\
$45,000-54,999$ & 14.5 & 18.0 & 49 & 32 & 19 \\
$55,000-59,999$ & 8.0 & 17.8 & 48 & 32 & 19 \\
$60,000-69,999$ & 14.9 & 17.6 & 46 & 34 & 19 \\
$70,000-84,999$ & 18.9 & 17.2 & 49 & 35 & 17 \\
$85,000-99,999$ & 12.2 & 16.4 & 43 & 34 & 22 \\
$100,000-119,999$ & 8.7 & 15.2 & 40 & 37 & 23 \\
$120,000-149,999$ & 4.8 & 14.0 & 36 & 38 & 25 \\
$150,000+$ & 2.9 & 10.9 & 33 & 36 & 31 \\
\hline
\end{tabular}

$100 \%$ LTV choice available only during this period. The majority of borrowers have a $95 \%$ LTV. On average, $13.4 \%$ of borrowers in the population have $0 \%$ down. This is because $16.8 \%$ of borrowers in the insured space have 100\% LTV mortgages and here we are adding FTHBs in the uninsured space to the calibration. We know very little about these borrowers, except that on average during the sample period they represent about $20 \%$ of FTHBs.

Potential FTHBs can usually qualify in more than one LTV category. Because there is a strong tendency for a household's LTV qualifying range to be constrained mainly at the lower end, the assignment of FTHBs to LTV categories proceeds iteratively, from low to high levels of LTV. The result of this iterative procedure is a pool of potential FTHBs in the household-level survey data that is representative of the FTHBs found in the CMHC loan-level data.

Note that while matching the joint distribution of income and down payment, we also match the unconditional income distribution. That is, we ensure that the 
Table 3.7: Loan-level data calibration: 2007 to 2008

Calibration variables for HRAM. Potential FTHBs are drawn from CFM based on whether their income, PTI, and LTV ratio characteristics match those in the loan-level data. Income is gross nominal household income. The distribution of LTV by income is based on the loan-level data. The fraction of FTHBs with an LTV of less than 80, i.e., outside of the insurance space, is based on CFM. The cross-sectional dispersion in $\mathrm{mp} /$ inc ( $\sigma$ in equation $(3.2)$ ) is 5.5 .

\begin{tabular}{lcccccc}
\hline $\begin{array}{l}\text { Income category } \\
(\$)\end{array}$ & $\begin{array}{c}\text { Frequency } \\
(\%)\end{array}$ & $\begin{array}{c}\text { PTI } \\
\text { mean }\end{array}$ & \multicolumn{5}{c}{ LTV } & $95 \%$ & $90 \%$ & $80 \%$ \\
\hline $0-24,999$ & 0.5 & 18.1 & 9.9 & 49 & 25.1 & 16 \\
$25,000-34,999$ & 2.8 & 18.2 & 12 & 45.7 & 23.4 & 19 \\
$35,000-44,999$ & 7.3 & 18.9 & 14.5 & 41.4 & 25.1 & 19 \\
$45,000-54,999$ & 11.7 & 18.9 & 14.5 & 39.3 & 27.2 & 19 \\
$55,000-59,999$ & 6.8 & 18.7 & 14.7 & 39.8 & 26.4 & 19 \\
$60,000-69,999$ & 14.5 & 18.6 & 14.9 & 39.1 & 27 & 19 \\
$70,000-84,999$ & 19.0 & 18.1 & 14.4 & 40.2 & 28.4 & 17 \\
$85,000-99,999$ & 14.2 & 17.6 & 13 & 37.6 & 27.5 & 22 \\
$100,000-119,999$ & 11.3 & 16.6 & 12.2 & 36.7 & 28.0 & 23 \\
$120,000-149,999$ & 7.2 & 15.3 & 10.7 & 34.9 & 29.4 & 25 \\
$150,000+$ & 4.7 & 12.7 & 8.3 & 30.6 & 30 & 31 \\
\hline
\end{tabular}

fraction of FTHBs in each of the 11 income categories matches what we observe in the mortgage origination data. The frequencies are given in column (2) of Table 3.6 for the 2005 calibration and column (2) of Table 3.7 for the 2007-2008 calibration.

\subsubsection{Housing Market}

So far we have discussed the demand for mortgage credit, with little discussion of the housing or rental markets. This is because once renters have sufficient income and wealth to purchase a starter home in their neighborhood, they will do so, subject to an idiosyncratic shock. The decision to rent is implicitly the complement of the decision to enter the housing market (abstracting from the household formation decision). Renters who qualify to enter the market but do not receive the idiosyncratic shock continue to rent. In this respect, an explicit modeling of the rental decision is not essential for addressing the issues at hand. The price of housing, however, which is determined exogenously from the model, plays an integral role, since it is an input in 
deciding which households can enter the market.

We calibrate the minimum house price for market entry using a combination of census metropolitan area (CMA) and population-weighted provincial house price data. Specifically, we use the average resale price based on the Canadian Real Estate Association housing data at the CMA level for those living in one of the 25 CMAs, and provincial prices for those living outside those areas. Between the two periods, house prices increase from just under $\$ 173,000$ to just over $\$ 203,000$ with substantial variation across cities. The average house price in Vancouver and Toronto, for example, is more than twice that of other Canadian cities Also outside of the household data are interest rates. Over the sample period, the average typical interest rate on a five-year fixed-rate mortgage increased from $4.93 \%$ to $5.50 \%$.

\subsubsection{Results}

We perform two sets of experiments. First, we calibrate HRAM to a base case using data from 2005. This captures the period prior to the sequence of macroprudential loosenings highlighted in Section 3.3. We then quantify the impacts of the loosening of the rules for insured mortgages on FTHBs. In the second set of experiments we calibrate HRAM to data from the loose period (2007-2008). This second set of experiments allows us to quantify the implications of macroprudential tightening on the set of FTHBs who were able to take advantage of the most generous mortgage terms in our sample. For the experiments, we assume that, for potential FTHBs in a given down payment and income category, the PTI shock that each household receives and the probability of buying a house are both unchanged from the relevant baseline scenario (no rule change) to the rule-change scenario. However, because the

pool of potential FTHBs itself changes in size as the rule change alters the extent of household qualification, across all down payment and income categories, the number of FTHBs will change. 
Thus, the impacts can occur on both the extensive and intensive margins. The extensive margin encompasses households that are newly included or excluded from the set of FTHBs as a result of a change in macroprudential rules; the intensive margin can be affected because with the PTI shock held constant, the mortgage size increases as the amortization period increases, and vice versa. In either case, the results can be interpreted as responses to how income and wealth constraints have changed with the new rule(s).

We first experiment with the impact of loosening on mortgage demand. For this case, we first calibrate the baseline FTHBs to the 2005 loan-level data. For the relaxation of the down payment to $0 \%$, we assume that the probability of buying at $0 \%$ is the same for potential FTHBs who qualify at $0 \%$ as for those who qualify at a $5 \%$ down payment, with the latter probability determined in the baseline calibration. When we do this experiment, we assume that households that qualified under the tighter policy still qualify under the looser policy. ${ }^{20}$

For the loosening experiments, we consider four different amortization changes. The variables in the first three rows in Table 3.8 were implemented in 2006, whereas the fourth row combines these into a hypothetical one-time policy move. We report three outcomes of the model: (i) the change in the percentage of qualified households, (ii) the change in the percentage of FTHBs, and (iii) the change in FTHB mortgage debt. The difference between the changes in the number of households that qualify and the households that purchase is a function of our calibration. If there was no calibration to the loan-level data, a greater number of households in lower income categories would be assigned as FTHBs in the model. These potential FTHBs, however, would in reality have less tendency to purchase a house, which may reflect preferences

\footnotetext{
${ }^{20}$ Note that otherwise, due to our assumption that households have a fixed PTI (meaning that a loosening of the amortization implies that a household purchases a larger house), it arises that some households would not be able to afford the down payment for the larger house. Since this is not an intended effect in the exercise, we essentially relax the fixed-GDS assumption for some baseline FTHBs, where necessary. Note that this gives an extensive margin effect that is the same as it would be if the preference shock specified a fixed mortgage amount instead.
} 
that the calibration helps to reflect. Recall the probability of buying a house is given by condition (3.9).

The first result is that a relaxation in the amortization from 25 to 30 years leads to a $4.5 \%$ increase in FTHBs and an $11.3 \%$ increase in mortgage demand. The second relaxation was amortization from 30 to 35 years, conditional on the first change in amortization having already happened. The increase in demand is smaller in this case, with an increase in entry of $2.7 \%$ and an increase in demand of $7.5 \%$. The smaller impact is because of the smaller percentage increase in amortization and because of the nonlinear effects of amortization on mortgage payments. The third row shows that further loosening had an even smaller effect - a $2 \%$ increase in entry and an increase in demand of $5.4 \%$. The fourth row measures the impact of changing the amortization from 25 to 40 years in one step rather than sequentially. The impacts on entry and demand are nearly identical to the sequential changes.

The fifth row in Table 3.8 considers the impact of keeping the amortization fixed at 40 years and changing the LTV from 95 to 100. This change was made in November 2006 by the government, and as we saw in Section 3.4.2, there was a $17 \%$ uptake in zero-down-payment mortgages. We observe a $129.7 \%$ increase in FTHBs and a $137.4 \%$ increase in mortgage demand. Clearly this is an overestimation of what we observe in the data. When we examine the impact of tightening from 100 to 95, we see that the impact is not symmetric. When we allow FTHBs to enter with zero savings, the only constraint is the income constraint. Many individuals therefore qualify to enter. Not everyone, however, enters the market. This is because we are not capturing behavioral features, such as aversion to having zero equity, preferences for renting, or aversion to debt by some households, which these results clearly imply are important given the very large pure-qualification effect.

The last two rows in the loosening panel consider the impact of house prices on FTHBs. In the model, prices do not respond endogenously to macroprudential 
Table 3.8: Impacts of loosening policy from the structural model

\begin{tabular}{|c|c|c|c|c|}
\hline Experin & & $\begin{array}{c}\Delta \text { in \# of } \\
\text { Qualified } \\
\text { Households (\%) }\end{array}$ & $\begin{array}{c}\Delta \text { in } \\
\text { \# of } \\
\text { FTHBs }(\%)\end{array}$ & $\begin{array}{c}\Delta \text { in FTHB } \\
\text { Mortgage } \\
\text { Debt (\%) }\end{array}$ \\
\hline \multicolumn{5}{|c|}{ Loosening: Calibrated to 2005 data } \\
\hline LTV & Amortization & & & \\
\hline 95 & 25 to $30 \mathrm{yrs}$ & 6.5 & 4.5 & 11.3 \\
\hline 95 & 30 to 35 yrs & 4.4 & 2.7 & 7.5 \\
\hline 95 & 35 to $40 \mathrm{yrs}$ & 3.1 & 2.0 & 5.4 \\
\hline 95 & 25 to $40 \mathrm{yrs}$ & 12.9 & 9.0 & 24.7 \\
\hline 95 to 100 & 40 yrs & 166.9 & 129.7 & 137.4 \\
\hline HP $\uparrow 2005$ to 2006 & unchanged & -6.2 & -4.1 & -2.5 \\
\hline HP $\uparrow 2005$ to 2008 & unchanged & -9.7 & -6.7 & -4.2 \\
\hline \multicolumn{5}{|c|}{ Tightening: Calibrated to $2007-2008$ data } \\
\hline LTV & Amortization & & & \\
\hline 95 & 40 to $35 \mathrm{yrs}$ & -3.5 & -2.1 & -5.3 \\
\hline 95 & 35 to $30 \mathrm{yrs}$ & -4.8 & -3.6 & -7.2 \\
\hline 95 & 30 to $25 \mathrm{yrs}$ & -7.3 & -5.1 & -10.4 \\
\hline 100 to 95 & $40 \mathrm{yrs}$ & -51.5 & -7.9 & -8.1 \\
\hline
\end{tabular}

rule changes. This experiment shows that if we allow house prices to increase to match the actual price increase observed between 2005 and 2007-2008, this would offset approximately $75 \%$ of the increase in affordability allowed by loosening the amortization from 25 to 40 years. To fully capture the effects of the macroprudential policy on house prices, general equilibrium effects would need to be incorporated, where housing supply elasticities would play a crucial role (see section 3.5.5).

For the tightening, we calibrate the model to the 2007-2008 loan-level data. This was a period when rules had been substantially loosened, and a tightening from this period would likely have put restrictions on FTHBs who entered with $0 \%$ equity and 35- to 40-year amortization. We consider four experiments. The first three are a tightening of the maximum allowable amortization, while the last is a tightening of the maximum allowable LTV from 100 to 95. A tightening of amortization from 40 to 35 years leads to a small reduction in FTHBs and mortgage demand. A tightening 
from 35 to 30 years leads to a $3.6 \%$ reduction in FTHBs entering the market and a $7.2 \%$ reduction in the demand for credit. This change in amortization, like a change from 30 to 25 years, has similar impacts on mortgage demand to a change in LTV. The change in the maximum allowable LTV from 100 to 95 has a $7.9 \%$ decrease in FTHBs and an $8.1 \%$ decrease in credit. Notice that the fraction of households that qualify falls more dramatically for a relatively smaller proportional change in the LTV - the impact also appears to be more on the extensive margin, through the change in qualification, rather than the intensive margin of average mortgage sizes. In Section 3.4.2 we argued that the wealth constraint was the most binding - this is where that constraint appears. Once the 100\% LTV mortgages are removed, households can no longer qualify with zero equity. Given our calibration exercise in Table 3.7, and equation (3.9) that maps income and LTV into purchasing probabilities, only $13.4 \%$ of the population of baseline FTHBs had zero down (16.8\% of the high-LTV FTHBs), and the impact on total credit from the LTV change is $8.1 \%$.

In addition to measuring the responses of FTHBs to hypothetical changes to income and wealth constraints, one can assess the impact of the combined changes in constraints over time. In Figure 3.3, we present the full path of credit growth in Canada, starting with the 2006 loosening of amortization and including all the tightening between 2008 and 2010. Here, total credit is the sum of $x_{i}^{D}$, or the sum of mortgage credit and other household credit. The impact on total credit growth is immediate upon loosening and tightening. Loosening leads to an increase in total credit while tightening leads to a contraction.

A key assumption in the calculation of cumulative effects pertains to the persistence of the individual rule-change effects. Figure 3.3 reflects the assumption that extensive margin effects are transitory one-off effects, which should, on balance, have a net effect of roughly zero on mortgage credit growth over the long term. This is because the loosening of rules should largely create a pull-forward effect, as households 
that had an underlying intention/preference to enter the housing market, independent of prevailing macroprudential rules, are able to enter sooner in the loosened periods. The tightening period beginning in 2008 eventually returned both the maximum amortization and LTV levels to their original pre-2006 states, at 25 years and $100 \%$. With the exception of some households that might never have been able to enter the housing market, had it not been for the loosened period, most of the extensive margin effects would amount to a shifting of FTHB entry from later periods into earlier periods. In other words, most of these FTHBs who entered would have eventually increased their financial assets or income sufficiently to enter the market, even without the looser period.

The intensive margin effects, in contrast, are more likely to have persisted for the entire period that they were in place. ${ }^{21}$ That is, throughout the period that a 40-year amortization was allowed, some FTHBs would continue to take out 40-year amortizations. Rather than being a shift in demand from one period to another, the distribution of mortgage characteristics should experience a sustained shift, as long as the new rules are held in place. The combination of these transitory and sustained effects gives the cumulative impact in Figure 3.3, leveling out at a $6 \%$ increase in the level of mortgage credit by 2012. Although this level increase will diminish over time, as the stock of longer-amortization mortgages are paid off, one could argue that the household debt-to-income level is higher than it otherwise would have been without this period of looser rules. So while the impacts of macroprudential rule changes have been difficult to determine in many settings, our simulations suggest that these changes may have been important and lasting.

Finally, we can also use HRAM to provide insights as to how tighter macroprudential policies can help increase the resilience of FTHBs, and potentially the financial system, to shocks. To do so, we simulate the cohort of entering FTHBs for two years

\footnotetext{
${ }^{21}$ The intensive margin effect is approximately the difference between the total percentage effect on FTHB mortgage credit and the percentage effect on the number of FTHBs.
} 
Figure 3.3: Impact of macroprudential loosening and tightening on credit growth

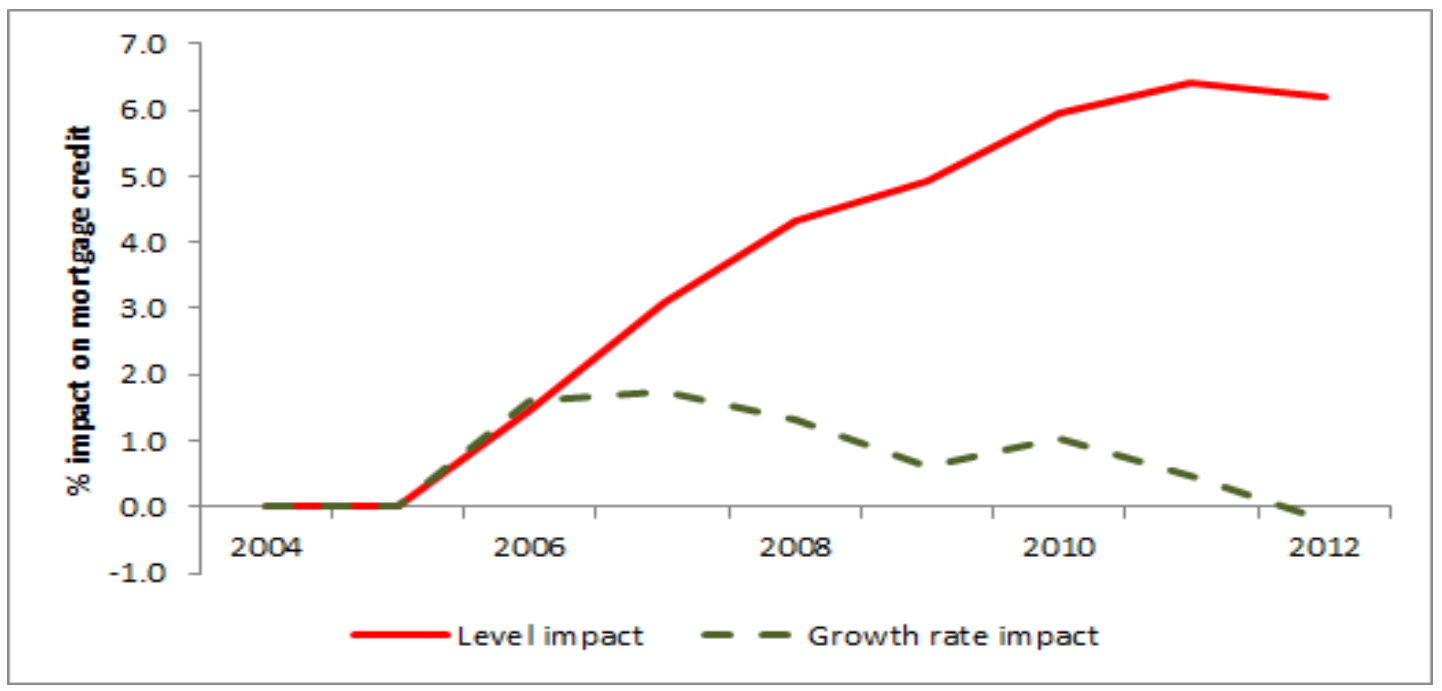

to examine to what extent they have sufficient financial assets to continue making their debt payments in the face of idiosyncratic unemployment shocks. More specifically, we examine the evolution of arrears for FTHBs, where a household is in arrears if a mortgage payment has been missed for 90 days. The simulation is performed under two scenarios: a baseline and an interest rate shock. For each scenario we quantify how different macroprudential policy can lower arrears for FTHBs. As in the loosening example above, we calibrate the baseline to the 2007-208 loan-level data. The maximum allowable LTV is therefore 100 and the maximum allowable amortization period is 40 years. The national unemployment rate is set at $7.9 \%$ (See Table 3.5), which determines the probability individuals lose their jobs and, depending on their financial wealth, default.

The alternative macroprudential policies we consider include the cases where the maximums are 95 for the LTV and 40 years for amortizations well as the case with 100 for LTV and 25 years for amortization. We also examine the combined effect of having the maximums at 95 for LTV and 25 years for amortization. The shock scenario involves a 2 percentage point increase in mortgage rates at the start of the second year, after our FTHBs have entered the market. The goal is to mimic interest 
rate risk at renewal. All else equal, the higher mortgage rates lead to an increase in arrears because the larger monthly mortgage payments more quickly reduce the savings of an unemployed household. ${ }^{22}$

Results from our simulations are shown in Table 3.9. Our outcome variable of interest is the average of the aggregate arrears rate over a two year horizon. The aggregate arrears rate is defined as the aggregate amount of mortgages in arrears over the entire amount of mortgages outstanding. We draw several conclusions from these simulations. First, the fall in arrears due to a tightening of the LTV constraint is much larger relative to a reduction in the amortization period under both the baseline and shock scenario. The reason for this result is that the tightening of the LTV constraint restricts the entry of FTHBs to those households with larger holdings of financial assets which can be drawn on to make mortgage payments, in the case of income loss. Second, the impact on arrears of a combination of tighter LTV and tighter amortization is only marginally higher than the sum of each change individually, suggesting that the impacts of these policies are largely orthogonal to one another.

Table 3.9: Impact of interest rate shocks on arrears

This table presents the percentage change in household arrears under different macroprudential scenarios. The exercise is calibrated to 2007-2008 loan-level data where the maximum LTV is 100 and the maximum amortization is 40 years. The baseline case is under a normal interest rate path and the shock scenario is the 200 basis point increase in rates at renewal.

\begin{tabular}{lccc}
\hline & LTV 95/AM 40 & LTV 100/AM 25 & LTV 95/AM 25 \\
\hline Baseline & -17.5 & -5.0 & -24.1 \\
Shock & -18.7 & -6.2 & -24.9 \\
\hline
\end{tabular}

\footnotetext{
${ }^{22}$ In reality, a 5-year fixed rate mortgage would not reflect rate changes until the mortgage is renewed. Instead, in these simulations we assign 1-year fixed-rate mortgages to our FTHBs, to accelerate the pass-through of interest rates and better illustrate their eventual impact. Note also that since macroprudential policies are only imposed at the time of origination, a substantial increase in the monthly mortgage payment does not imply households will violate the income constraint provided the monthly mortgage payments are being made.
} 


\subsubsection{Discussion}

The results of the experiments suggest that wealth constraints are more effective than income constraints at affecting mortgage demand, particularly on the extensive margin, for a given proportional change and the given starting points of policy parameters (95\% maximum LTV and maximum 25-year amortization for insured mortgages). Income constraints, however, are just as effective as wealth constraints for high-wealth homebuyers. The focus of the empirical analysis and the model, however, is on mortgage demand, and ignores some aspects of the general market for housing as well as potential supply effects. In this section we discuss how market participants other than buyers might react to macroprudential policy, affecting the interpretation of our results.

We are currently abstracting from the response of lenders in the model. As a response to tighter macroprudential regulation, for example, there are two potential responses that could lead to lower rates. First, tightening can reduce the borrowers' risk, which could lead lenders to reduce rates. Given that financial institutions do not face default risk in this market, this seems unlikely. Second, since tightening can lead some potential buyers to be disqualified from accessing mortgage insurance, financial institutions might respond by easing rates (moral hazard), subject to the mortgage still being profitable. This could be a response to a tightening of amortization, since amortization and rates are alternatives that could be adjusted in order for a household to meet the income constraint. Interest rates and LTV, however, are not substitutes, therefore we would not expect financial institutions to lower rates in response to a tightening of the LTV. In both instances, the macroprudential policy will be less effective. In the context of our results, the impact of tightening the income constraint will be smaller than what we estimate.

The model abstracts from other factors as well, including the possible effects from rule changes on expected housing returns. A loosening could prompt a pull-forward of 
demand not only because of easier conditions for qualification, but also in anticipation that demand, and thus house prices, will be stronger going forward. Conversely, a tightening could at least temporarily influence sellers to accept lower-than-otherwise prices in the belief that demand would weaken. While this could contribute to the impacts from the rule changes, it would likely amount to one-off effects that would roughly net-out to zero over time; any pull-forward would not indefinitely continue to accumulate, and would certainly not continue once the amortization and LTV rules had returned to their original pre-2006 states. Nevertheless, to the extent that such factors could obscure the estimation of the effects of interest, i.e., on wealth and income constraints, and on mortgage debt levels, they would still be important.

Another feature not captured in HRAM is the market response in terms of house prices. Although an endogenous explanation for house prices is beyond the scope of the model, the model irrespectively provides insight into the possible impacts of macroprudential rules. The potential benefits of a loosening on affordability could be at least partially lost through market overheating; however, this would be conditional on the elasticity of supply over a given time horizon, thus rule changes interact with the ability of housing supply to respond to increased demand. Rapid loosening could be more likely to induce house price increases if the expansion in demand outpaces supply, so as to not achieve the intended benefits for affordability, at least in the short term. Over a longer time horizon, of course, the elasticity of supply should increase.

In the opposite case of a rule-tightening, though, any endogenous effect on house prices would serve to mitigate the negative affordability impact. This should diminish the concern about negative side effects from measures implemented to counteract mushrooming household debt. In either case, the relative elasticities of short-term versus long-term supply are worthy of consideration. 


\subsection{Conclusion}

This paper analyzes the impact of key macroprudential housing finance rule changes in Canada on household borrowing behavior and mortgage credit. From changes in consumer demand, we find that LTV constraints, which work through the wealth channel, are effective housing finance tools. Given that the average household is able to meet changes in cash flow, we conclude that, at least with the types of changes we observe to amortization, that changes directed at household repayment constraint are less effective. Households are attracted to these products, however, they are not binding.

An important contribution of this paper is the use of microsimulation modeling to capture the interactions of multiple policy tools and the non-linearities in consumer responses. This model imposes some structure on how we interpret the data while still being highly flexible in capturing nonlinear responses that more traditional, rational forward-looking dynamic stochastic general equilibrium models generally have difficulty capturing. The model allows us to map the impact of a policy change on the percentage of FTHBs who enter the market and their demand for credit. The results of our microsimulation model suggest that the wealth constraint has the largest impact on the number of FTHBs who enter the housing market and amount of debt that they hold. However, the impact of changes in amortization, which affect the income constraint, do affect high-wealth households. Finally, we show that LTV policies seem to reduce the impact of interest rate shocks on household vulnerabilities relative to income-based policies.

A caveat of our results is that we have taken as given that lenders are able to change the supply of credit exogenously in response to changes in macroprudential policy. This appears reasonable, given that banks do not face default risk in the Canadian (insured) mortgage market. However, if there is a tightening, banks might react strategically to price mortgages in a way that partially offsets changes in macro- 
prudential policies. More importantly, we do not capture general equilibrium effects. A relaxation of mortgage insurance guidelines leads to entry of FTHBs, which can lead to house price appreciation, which leads to further entry and greater house price appreciation. This can affect both current and future mortgage demand in a way that is not captured in the model. 


\section{Bibliography}

Aivazian, V. A., Y. Ge, and J. Qiu (2005). The impact of leverage on firm investment: Canadian evidence. Journal of Corporate Finance 11(1), 277 - 291.

Allen, J., R. Clark, and J. F. Houde (2014). Price dispersion in mortgage markets. Journal of Industrial Economics 62, 377-416.

Allen, J., T. Grieder, B. Peterson, and T. Roberts (2017). The impact of macroprudential housing finance tools in canada. Journal of Financial Intermediation.

Anenberg, E. and P. Bayer (2013). Endogenous sources of volatility in housing markets: The joint buyer-seller problem. NBER working paper No. 18980.

Angelini, P., S. Neri, and F. Panetta (2012, July). Monetary and macroprudential policies. Working Paper Series 1449, European Central Bank.

Angrist, J. D. and A. B. Krueger (2000). Empirical strategies in labor economics. In O. Ashenfelter and D. Card (Eds.), Handbook of Labor Economics, Volume 3A. Amsterdam: Elsevier Science.

Balli, H. O. and B. E. Sørensen (2013). Interaction effects in econometrics. Empirical Economics 45(1), 583-603.

Baster, C. and C. Koch (2014). Higher bank capital requirements and mortgage pricing: Evidence from the countercyclical capital buffer. Bank of International Settlements, Mimeo.

Bernanke, B., M. Gertler, and S. Gilchrist (1996, February). The Financial Accelerator and the Flight to Quality. The Review of Economics and Statistics 78(1), $1-15$.

Bollinger, C. R. and A. Chandra (2005). Iatrogenic specification error: A cautionary tale of cleaning data. Journal of Labour Economics 23(2), 235-257. 
Brueckner, J. (1994). The demand for mortgage debt: Some basic results. Journal of Housing Economics 3, 251-262.

Cabello, M., J. Lupú, and E. Minaya (2017). Empirical analysis of macroprudential policies in peru: The effects of dynamics provisioning and conditional reserve requirements. mimeo, BIS CCA CGDFS Working Group.

Cerutti, E., S. Claessens, and L. Laeven (2017). The use and effectiveness of macroprudential policies: New evidence. Journal of Financial Stability 28, 203-224.

Chaney, T., D. Sraer, and D. Thesmar (2012, October). The Collateral Channel: How Real Estate Shocks Affect Corporate Investment. American Economic Review 102(6), 2381-2409.

Claessens, S. (2015, December). An Overview of Macroprudential Policy Tools. Annual Review of Financial Economics 7(1), 397-422.

Corbae, D. and E. Quintin (2015). Leverage and the Foreclosure Crisis. Journal of Political Economy 123(1), 1-65.

Crawford, A. (2015). Building stable mortgage markets: Lessons from Canada's experience. Journal of Money, Credit and Banking 47, 81-86.

Davidoff, T. (2016). Supply constraints are not valid instrumental variables for home prices because they are correlated with many demand factors. Critical Review of Finance 5(2), 177-206.

Davis, M. A. and J. Heathcote (2005). Housing and the business cycle. International Economic Review 46(3), 751-784.

de Araujo, D. K. G., J. B. R. B. Barroso, and R. B. Gonzalez (2016, November). LoanTo-Value Policy and Housing Loans: effects on constrained borrowers. Working Papers Series 445, Central Bank of Brazil, Research Department. 
Fazzari, S. M., R. G. Hubbard, and B. C. Petersen (1988). Financing Constraints and Corporate Investment. Brookings Papers on Economic Activity 19(1), 141-206.

Frank, M. Z. and V. K. Goyal (2009). Capital structure decisions: Which factors are reliably important? Financial Management 38(1), 1-37.

Fuenzalida, M. and J. Ruiz-Tagle (2011, 06). Household Financial Vulnerability. In Financial Stability, Monetary Policy, and Central Banking, Volume 15 of Central Banking, Analysis, and Economic Policies Book Series, Chapter 10, pp. 299-326. Central Bank of Chile.

Galati, G. and R. Moessner (2013). Macroprudential policy - A literature review. Journal of Economic Surveys 27(5), 846-878.

Gómez, E., L. Angélica, J. C. Mendoza, and A. Murcia (2017). Evaluating the impact of macroprudential policies on credit growth in colombia. BIS Working Paper No. 634.

Gorman, W. M. (1964). Professor friedman's consumption function and the theory of choice. Econometrica 32(1/2), 189-197.

Greenwald, D. (2015). The mortgage credt channel of macroeconomic transmission. mimeo.

Gupta, A. and V. Kapur (2000). Microsimulation in government policy and forecasting. North-Holland: Amsterdam.

Han, L., C. Lutz, and B. Sand (2016). The effects of macroprudential mortgage insurance regulation during a housing boom: Evidence from Canada. Mimeo.

Harding, A. (1996). Microsimulation and public policy. North-Holland: Amsterdam.

Harvey, C. R. (2017). Presidential address: The scientific outlook in financial economics. Journal of Finance 72(4), 1399-1440. 
Herrala, R. and K. Kauko (2007). Household loan loss risk in Finland : estimations and simulations with micro data. Research Discussion Papers 5/2007, Bank of Finland.

Huynh, K. P., R. J. Petrunia, and M. Voia (2010). The impact of initial financial state on firm duration across entry cohorts. Journal of Industrial Economics 58(3), 661-689.

Igan, D. O. and H. Kang (2011, December). Do Loan-To-Value and Debt-To-Income Limits Work? Evidence From Korea. IMF Working Papers 11/297, International Monetary Fund.

IMF (2013). Key aspects of macroprudential policy-background paper. International Monetary Fund, June.

Jensen, M. (1986). Agency costs of free cash flow, corporate finance, and takeovers. American Economic Review 76(2), 323-29.

Jensen, M. C. and W. H. Meckling (1976). Theory of the firm: Managerial behavior, agency costs and ownership structure. Journal of Financial Economics 3(4), 305 -360 .

Johansson, M. W. and M. Persson (2006). Swedish households' indebtedness and ability to pay: a household level study. Working paper series, Sveriges Riksbank.

Kaplan, S. N. and L. Zingales (1997). Do investment-cash flow sensitivities provide useful measures of financing constraints? The Quarterly Journal of Economics 112(1), 169-215.

Koenker, R. (2004). Quantile regression for longitudinal data. Journal of Multivariate Analysis $91(1), 74-89$. 
Kuttner, K. N. and I. Shim (2016). Can non-interest rate policies stabilize housing markets? Evidence from a panel of 57 economies. Journal of Financial Stability $26(\mathrm{C}), 31-44$.

Lambertini, L., C. Mendicino, and M. Punzi (2013). Leaning against boombust cycles in credit and housing prices. Journal of Economic Dynamics and Control 37, 15001522.

Lamont, O. (1997). Cash flow and investment: Evidence from internal capital markets. The Journal of Finance 52(1), 83-109.

Lang, L., E. Ofek, and R. Stulz (1996). Leverage, investment, and firm growth. Journal of Financial Economics 40(1), 3 - 29.

Levin, G., C. López, and F. Lopez-Gallo (2017). The impact of expected losses provisioning on credit growth: the case of mexico. mimeo, BIS CCA CGDFS Working Group.

Mendes, R. and S. Murchinson (2014). Should forward guidance be backward-looking? Bank of Canada Review (Autumn).

Michelangeli, V. and M. Pietrunti (2014). A Microsimulation Model to evaluate Italian Households Financial Vulnerability. International Journal of Microsimulation 7(3), 53-79.

Modigliani, F. and M. H. Miller (1958). The cost of capital, corporation finance and the theory of investment. The American Economic Review 48(3), 261-297.

Mordel, A. and N. Stephens (2015). Residential mortgage securitization in Canada: A Review. Bank of Canada Financial System Review (December).

Myers, S. C. (1977). Determinants of corporate borrowing. Journal of Financial Economics 5(2), $147-175$. 
Myers, S. C. (1984). The capital structure puzzle. The Journal of Finance 39(3), $574-592$.

Rajan, R. and L. Zingales (1995). What do we know about capital structure? some evidence from international data. The Journal of Finance 50(5), 1421-1460.

Rousseeuw, P. and A. Leroy (1987). Robust Regression and Outlier Detection. New York: WileyInterscience.

Saiz, A. (2010, August). The Geographic Determinants of Housing Supply. The Quarterly Journal of Economics 125(3), 1253-1296.

Schembri, L. (2014). Housing finance in Canada: Looking back to move forward. National Institute Economic Review 230, R45-R57.

Stein, J. C. (2003). Chapter 2 - agency, information and corporate investment. In G. M. Constantinides, M. Harris, and R. M. Stulz (Eds.), Corporate Finance, Volume 1 of Handbook of the Economics of Finance, pp. 111 - 165. Elsevier.

Stulz, R. M. (1990). Managerial discretion and optimal financing policies. Journal of Financial Economics 26(1), 3-27.

Townsend, R. M. (1979). Optimal contracts and competitive markets with costly state verification. Journal of Economic Theory 21(2), 265 - 293.

Tukey, J. W. (1962, March). The future of data analysis. The Annals of Mathematical Statistics 33(1), 1-67. 